\title{
A Model for Dissolution of Lime in Steelmaking Slags
}

\author{
RAHUL SARKAR, USHASI ROY, and DINABANDHU GHOSH
}

In a previous study by Sarkar et al. (Metall. Mater. Trans. B 46B:961 2015), a dynamic model of the LD steelmaking was developed. The prediction of the previous model (Sarkar et al. in Metall. Mater. Trans. B 46B:961 2015) for the bath (metal) composition matched well with the plant data (Cicutti et al. in Proceedings of 6th International Conference on Molten Slags, Fluxes and Salts, Stockholm City, 2000). However, with respect to the slag composition, the prediction was not satisfactory. The current study aims to improve upon the previous model Sarkar et al. (Metall. Mater. Trans. B 46B:961 2015) by incorporating a lime dissolution submodel into the earlier one. From the industrial point of view, the understanding of the lime dissolution kinetics is important to meet the ever-increasing demand of producing low-P steel at a low basicity. In the current study, three-step kinetics for the lime dissolution is hypothesized on the assumption that a solid layer of $2 \mathrm{CaO} \cdot \mathrm{SiO}_{2}$ should form around the unreacted core of the lime. From the available experimental data, it seems improbable that the observed kinetics should be controlled singly by any one kinetic step. Accordingly, a general, mixed control model has been proposed to calculate the dissolution rate of the lime under varying slag compositions and temperatures. First, the rate equation for each of the three rate-controlling steps has been derived, for three different lime geometries. Next, the rate equation for the mixed control kinetics has been derived and solved to find the dissolution rate. The model predictions have been validated by means of the experimental data available in the literature. In addition, the effects of the process conditions on the dissolution rate have been studied, and compared with the experimental results wherever possible. Incorporation of this submodel into the earlier global model (Sarkar et al. in Metall. Mater. Trans. B 46B:961 2015) enables the prediction of the lime dissolution rate in the dynamic system of LD steelmaking. In addition, with the inclusion of this submodel, significant improvement in the prediction of the slag composition during the main blow period has been observed.

DOI: $10.1007 / \mathrm{s} 11663-016-0659-0$

(c) The Minerals, Metals \& Materials Society and ASM International 2016

\section{INTRODUCTION}

IN their recent publication, ${ }^{[1]}$ the authors developed a dynamic model for predicting the bath and slag compositions during blowing in a 160 -ton LD converter. While model predictions for bath compositions appeared to be in relatively good agreement with measurements in an actual LD converter by Cicutti et al., ${ }^{[2]}$ those for the slag compositions did not correspond well to the actual values. Predictions for percent $\mathrm{CaO}$ in slag were too high and consequently those for percent $\mathrm{FeO}$ were too low. Among the assumptions made in the model, ${ }^{[1]}$ one was the uniform dissolution of lime during the blowing period. The model thus lacked a proper submodel for lime dissolution which might have resulted in the observed incongruity with the real values. The current study aims to develop a submodel for lime dissolution in steelmaking slags and study the effects of different process variables on dissolution rates. Finally, this submodel would be

RAHUL SARKAR and USHASI ROY, Researchers, are with Research and Development, Tata Steel Limited, Jamshedpur, India. DINABANDHU GHOSH, Professor, is with the Department of Metallurgical and Materials Engineering, Jadavpur University, Kolkata, 700032, India. Conatct e-mail: rahulsarkar.jumet@gmail.com

Manuscript submitted August 10, 2015.

Article published online April 11, 2016. incorporated into the global model for dynamically calculating lime dissolution rates with the aim of improving upon the predictions for slag compositions.

In the context of LD steelmaking, understanding dissolution kinetics of lime is imperative for several reasons. Lime constitutes a significant part of the total expenses for raw materials, and cutting down on lime consumption would considerably reduce the overall cost of steelmaking. A far more important reason is to get rid of free lime which is a perennial problem for operating steel plants. For conditions pertinent to Tata Steel, the amount of free lime in slags varies in the range from 5 to $10 \mathrm{pct},{ }^{[3]}$ and this limits its usage as a suitable building material. Another key motivation to study lime dissolution is to produce low-P steels with low-basicity slags. LD shops in Tata Steel typically operate in the basicity range from 3.2 to 3.8 , and recently, there has been an increasing drive to reduce the basicity of LD slags without compromising on turndown phosphorus. Process conditions, sequence of lime addition, lime particle size, etc. may be controlled within permissible limits to achieve this goal, but first, the effects of these parameters on turndown slag conditions must be understood. A fundamental study on lime dissolution in steelmaking slags is necessary because it plays a very important role in achieving the desired slag composition at turndown. 


\section{MODEL FORMULATION}

Reaction between solid $\mathrm{CaO}$ and $\mathrm{SiO}_{2}$ (as $\mathrm{SiO}_{4}{ }^{4-}$ ions) in slags results in the formation of calcium silicates, the experimental evidence for which may be found in the studies of several researchers. ${ }^{[4]}$ The type of silicates formed depends on slag conditions (primarily slag basicity and $\mathrm{FeO}$ content). In the current study, it is assumed that the reaction between solid $\mathrm{CaO}$ and $\mathrm{SiO}_{2}$ in slags results only in the formation of solid $2 \mathrm{CaO} \cdot \mathrm{SiO}_{2}$ which forms a layer around the unreacted core of $\mathrm{CaO}$. Under such conditions, further reaction between $\mathrm{CaO}$ and $\mathrm{SiO}_{2}$ would require the diffusion of $\mathrm{SiO}_{2}$ from the slag through the solid $2 \mathrm{CaO} \cdot \mathrm{SiO}_{2}$ layer to the interface between the unreacted $\mathrm{CaO}$ and $2 \mathrm{CaO} \cdot \mathrm{SiO}_{2}$. The kinetic steps involved in the dissolution process may then be summarized as:

1. Slag-film diffusion This step involves the diffusion of $\mathrm{SiO}_{2}$ from the bulk slag through the slag-film boundary layer formed around solid $2 \mathrm{CaO} \cdot \mathrm{SiO}_{2}$

2. Product-layer diffusion This involves the diffusion of $\mathrm{SiO}_{2}$ through the $2 \mathrm{CaO} \cdot \mathrm{SiO}_{2}$ layer formed around the unreacted core of $\mathrm{CaO}$.

3. Interfacial reaction It involves the reaction between solid $\mathrm{CaO}$ and $\mathrm{SiO}_{2}$ at the interface between unreacted $\mathrm{CaO}$ and the solid $2 \mathrm{CaO} \cdot \mathrm{SiO}_{2}$. A schematic representation of these steps for a spherical $\mathrm{CaO}$ particle is shown in Figure 1.

Experimental study on lime dissolution in steelmaking slags have been done by several researchers. ${ }^{[4-10]}$ Modeling studies on lime dissolution have been relatively less but still available. ${ }^{[11-13]}$ While several insights about the dissolution of lime in slags are available from these studies, none of them provide a definite conclusion about the rate-controlling step. A majority of the experimental and modeling studies on cylindrical lime particles assumes diffusion through the slag film as rate-controlling, referring to the study by Matsushima et al. ${ }^{[4]}$ However, Matsushima et al.' $\mathrm{s}^{[4]}$ conclusion that slag-film diffusion is rate-controlling is not corroborated by their experimental data. They argued that an increase in dissolution rates with the increasing speeds of revolution (of the rotating lime cylinder) confirms that slag-film diffusion is rate-controlling but even in case of mixed control rates would increase with increase in the speed of revolution. Furthermore, plots of $f(X) v s t$ for their experimental data do not confirm that slag-film diffusion is rate-controlling. Guo et al.' $\mathrm{s}^{[10]}$ experimental results for dissolution of spherical lime particles in blast furnace slags clearly show three regimes in which three different mechanisms control the rate. For rectangular specimens, Deng et al.' $\mathrm{s}^{[7]}$ experiments indicate that diffusion through the product layer may be rate-controlling. However, the number of data points reported by Deng et al. ${ }^{[7]}$ is too less to conclude anything decisive about the rate-controlling step.

In view of the above, the current authors debunk the hypothesis made in several previous investigations (especially those on cylindrical lime specimens) that slag-film diffusion controls the overall kinetics of lime dissolution in steelmaking slags. It is further argued that in a real steelmaking process where slag conditions like basicity, $\mathrm{FeO}$ content, temperature etc. are continually varying during the blow it seems unlikely that a single mechanism will be rate-controlling throughout. Rather, a mixed control model that takes into account contributions from the all the three (hypothetical) kinetic steps would be more appropriate. Thus in the current study, mixed control models have been developed for calculating dissolution rates of lime.

\section{A. Model Assumptions}

Apart from the basic assumption about the formation of solid $2 \mathrm{CaO} \cdot \mathrm{SiO}_{2}$, the following are the main assumptions of the model:

1. At the interface between the unreacted lime and the solid $2 \mathrm{CaO} \cdot \mathrm{SiO}_{2}$ layer, equilibrium conditions are attained.

2. Steady-state conditions are assumed to prevail, except in some cases where a pseudo-steady-state approximation has been made.

3. Diffusion of only $\mathrm{SiO}_{2}$ is considered. Diffusion of other slag constituents like $\mathrm{FeO}, \mathrm{P}_{2} \mathrm{O}_{5}$, etc. is not considered.

4. Diffusion is primarily considered to be taking placing along one principal direction.

5. Different geometries of lime specimen have been considered, but it has been assumed that lime particles of a particular geometry retain their original shape.

\section{B. Governing Equations}

The initial part of the model development involves the derivation of rate equations for each of the three rate-controlling steps for three different lime geometries. After that rate equations for mixed control kinetics have been derived for each of these geometries.

\section{Cylindrical specimen}

a. Slag-film diffusion control. Figure 2 gives a schematic representation of a cylindrical lime specimen in slag and the concentration profiles for slag-film diffusion control. A shell mass balance for the species $\mathrm{SiO}_{2}$ over a cylindrical shell in the slag-film of radius $r$, thickness $\Delta r$, and length $L$ gives (when $\Delta r \rightarrow 0$ ):

$$
\frac{\mathrm{d}}{\mathrm{d} r}\left(r N_{\mathrm{SiO}_{2}(-r)}\right)=0 \text {. }
$$

Integrating Eq. [1] and using the relationship between $J_{\mathrm{SiO}_{2}(-r)}^{*}$ and $N_{\mathrm{SiO}_{2}(-r)}$ as ${ }^{[14]}$

$$
\frac{J_{\mathrm{SiO}_{2}(-r)}^{*}}{\left(1-x_{\mathrm{SiO}_{2}}\right)}=N_{\mathrm{SiO}_{2}(-r)} \text {. }
$$

we get

$$
\frac{J_{\mathrm{SiO}_{2}(-r)}^{*}}{\left(1-x_{\mathrm{SiO}_{2}}\right)}=\frac{C_{1}}{r} .
$$

Using Fick's first law, ${ }^{[8]}$ the relation between $x_{\mathrm{SiO}_{2}}$ and $C_{\mathrm{SiO}_{2}}$ and substituting in Eq. [3], we get 


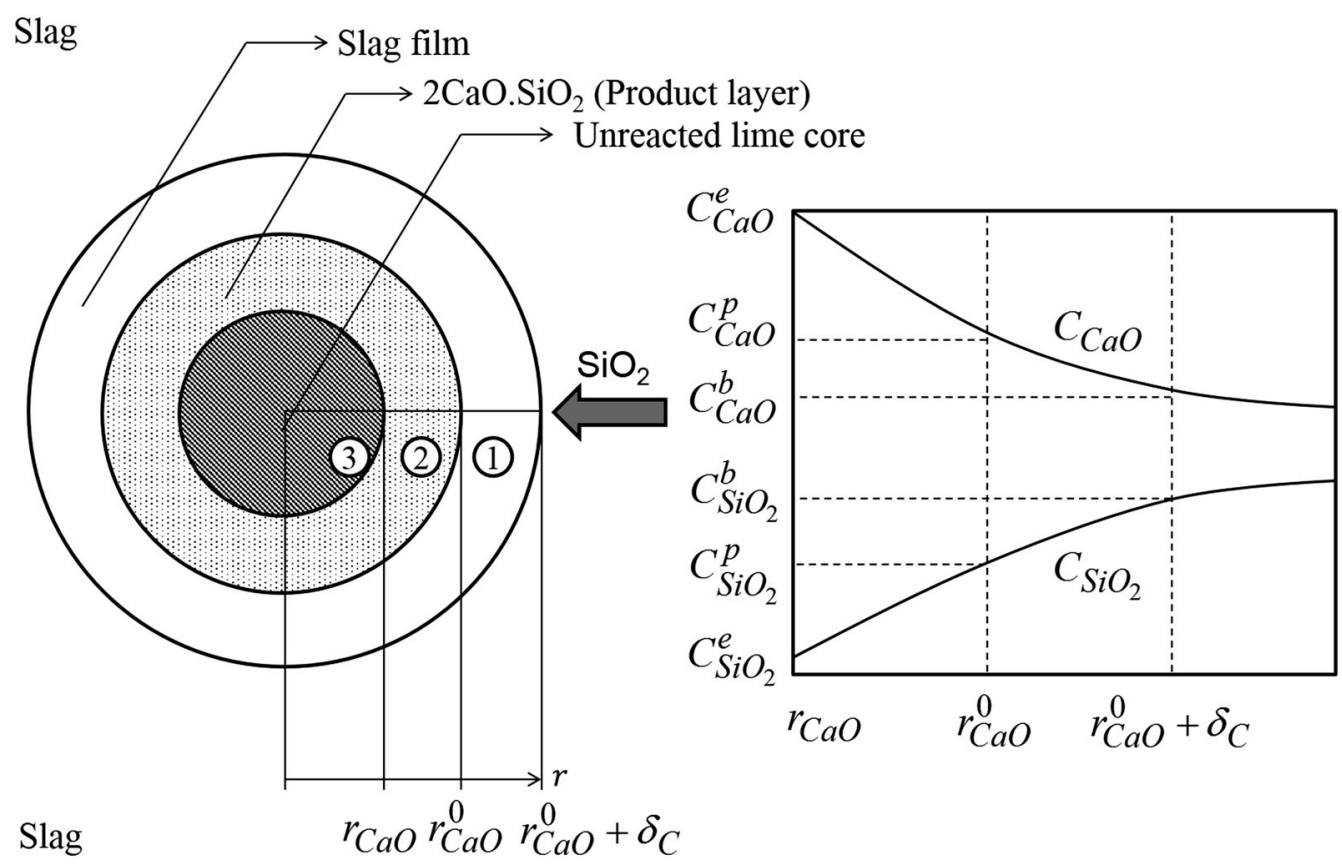

Fig. 1-Schematic representation of a $\mathrm{CaO}$ particle in slag and the hypothetical kinetic steps in the dissolution process.

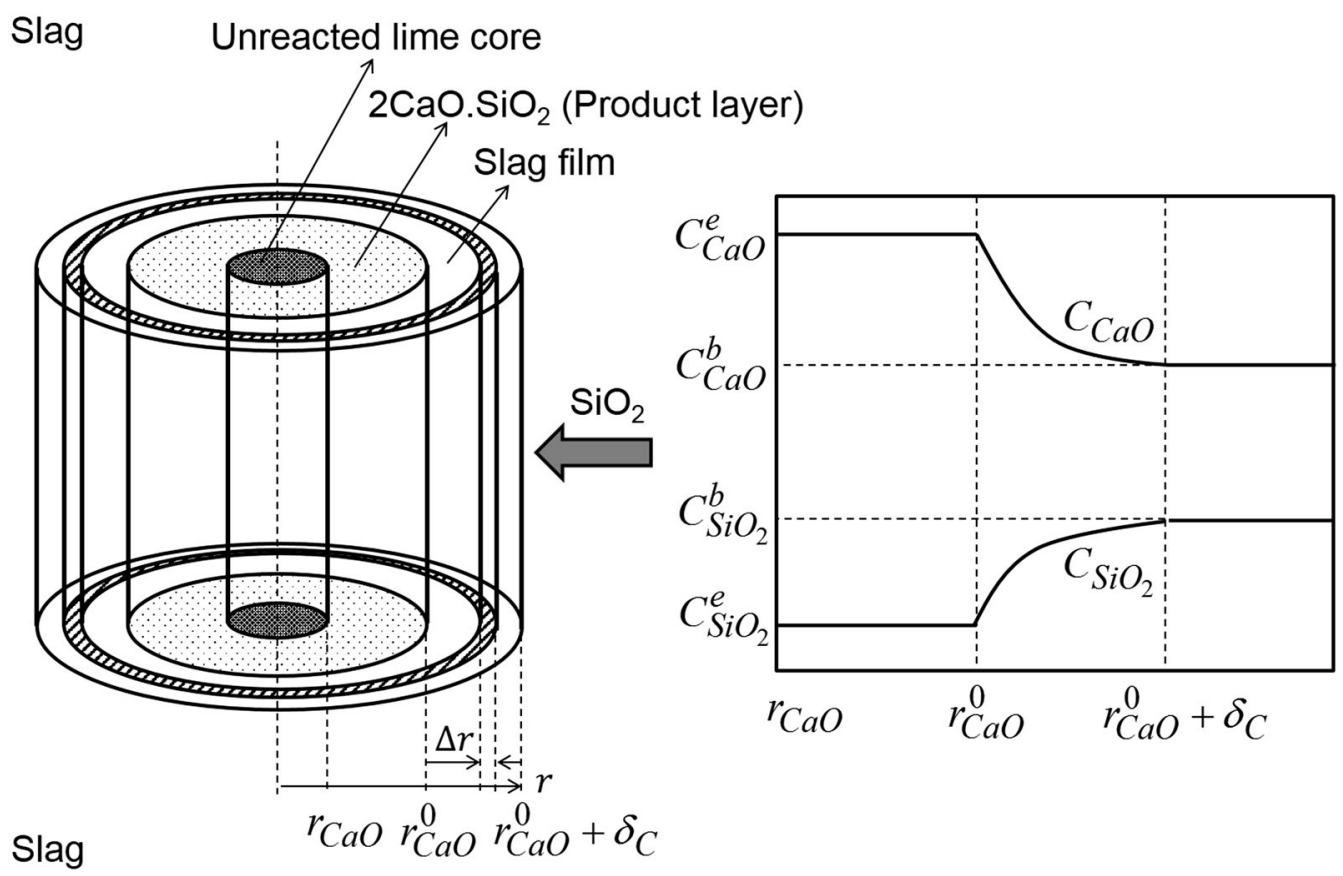

Fig. 2-Shell mass balance for a cylindrical $\mathrm{CaO}$ particle in slag and schematic concentration profiles for slag-film diffusion control.

$$
\frac{1}{\left(\rho_{\mathrm{s}}-C_{\mathrm{SiO}_{2}}\right)} \cdot \frac{\mathrm{d} C_{\mathrm{SiO}_{2}}}{\mathrm{~d} r}=\frac{C_{2}}{r} .
$$

Integrating Eq. [4] with the boundary conditions

$$
\left.\begin{array}{lll}
C_{\mathrm{SiO}_{2}}=C_{\mathrm{SiO}_{2}}^{e} & \text { at } & r=r_{\mathrm{CaO}}^{0} \\
C_{\mathrm{SiO}_{2}}=C_{\mathrm{SiO}_{2}}^{b} & \text { at } & r=r_{\mathrm{CaO}}^{0}+\delta_{C}
\end{array}\right\} \text {. }
$$

we obtain the concentration profile for $\mathrm{SiO}_{2}$ as

$$
\ln \left(\frac{\rho_{\mathrm{s}}-C_{\mathrm{SiO}_{2}}^{e}}{\rho_{\mathrm{s}}-C_{\mathrm{SiO}_{2}}}\right)=\ln \left(\frac{\rho_{\mathrm{s}}-C_{\mathrm{SiO}_{2}}^{e}}{\rho_{\mathrm{s}}-C_{\mathrm{SiO}_{2}}^{b}}\right) \cdot \frac{\ln \left(\frac{r}{r_{\mathrm{CaO}}^{0}}\right)}{\ln \left(\frac{r_{\mathrm{COO}}^{0}+\delta_{\mathrm{C}}}{r_{\mathrm{CaO}}^{0}}\right)} .
$$

The molar rate of diffusion $\left.W_{\mathrm{SiO}_{2}(-r)}\right|_{r}$ is given as 


$$
\left.W_{\mathrm{SiO}_{2}(-r)}\right|_{r}=\left.2 \pi r L \cdot N_{\mathrm{SiO}_{2}(-r)}\right|_{r}=\frac{2 \pi L \rho_{s} D_{s} \ln \left(\frac{\rho_{s}-C_{\mathrm{SiO}_{2}}^{e}}{\rho_{s}-C_{\mathrm{SiO}_{2}}^{b}}\right)}{\ln \left(\frac{r_{\mathrm{CaO}}^{0}+\delta_{\mathrm{C}}}{r_{\mathrm{CaO}}^{0}}\right)} .
$$

Since all the kinetic steps are in series, and using the stoichiometry of the reaction

$$
2 \mathrm{CaO}(\mathrm{s})+\left(\mathrm{SiO}_{2}\right)=2 \mathrm{CaO} \cdot \mathrm{SiO}_{2}(\mathrm{~s})
$$

we get

$\left.W_{\mathrm{SiO}_{2}(-r)}\right|_{r}=\left.W_{\mathrm{SiO}_{2}(-r)}\right|_{r_{\mathrm{CaO}}}=-\left.\frac{\mathrm{d} n_{\mathrm{SiO}_{2}}}{\mathrm{~d} t}\right|_{r_{\mathrm{CaO}}}=-\left.\frac{1}{2} \frac{\mathrm{d} n_{\mathrm{CaO}}}{\mathrm{d} t}\right|_{r_{\mathrm{CaO}}}$.

Substituting $\left.W_{\mathrm{SiO}_{2}(-r)}\right|_{r}$ in Eq. [8] and rewriting $n_{\mathrm{CaO}}$ in terms of $r_{\mathrm{CaO}}$ we get

$$
-r_{\mathrm{CaO}} \frac{\mathrm{d} r_{\mathrm{CaO}}}{\mathrm{d} t}=\frac{2 \rho_{\mathrm{s}} D_{\mathrm{s}} \ln \left(\frac{\rho_{s}-C_{\mathrm{SiO}_{2}}^{e}}{\rho_{s}-C_{\mathrm{SiO}_{2}}^{b}}\right)}{\rho_{\mathrm{CaO}} \ln \left(\frac{r_{\mathrm{CaO}}^{0}+\delta_{\mathrm{C}}}{r_{\mathrm{CaO}}^{0}}\right)}
$$

Integrating Eq. [9] within proper limits and replacing $r_{\mathrm{CaO}}$ in terms of $X$ we get

$$
X=\frac{4 \rho_{\mathrm{s}} D_{\mathrm{s}} \ln \left(\frac{\rho_{\mathrm{s}}-C_{\mathrm{Si}_{2}}^{e}}{\rho_{\mathrm{s}}-C_{\mathrm{SiO}_{2}}^{b}}\right)}{\rho_{\mathrm{CaO}} r_{\mathrm{CaO}}^{0}{ }^{2} \ln \left(\frac{r_{\mathrm{CaO}}^{0}+\delta_{\mathrm{C}}}{r_{\mathrm{CaO}}^{0}}\right)} t .
$$

Equation [10] is the integrated rate equation for slag-film diffusion for cylindrical geometry.

b. Product-layer diffusion control. Figure 3 gives a schematic representation of the concentration profile for a cylindrical lime specimen when the diffusion through the product $\left(2 \mathrm{CaO} \cdot \mathrm{SiO}_{2}(\mathrm{~s})\right)$ layer controls the overall rate. Proceeding in the same way as above and integrating using the pseudo steady-state assumption ${ }^{[15]}$ for the boundary conditions,

$$
\left.\begin{array}{lll}
C_{\mathrm{SiO}_{2}}=C_{\mathrm{SiO}_{2}}^{e} & \text { at } & r=r_{\mathrm{CaO}} \\
C_{\mathrm{SiO}_{2}}=C_{\mathrm{SiO}_{2}}^{b} & \text { at } & r=r_{\mathrm{CaO}}^{0}
\end{array}\right\} .
$$

The concentration profile for $C_{\mathrm{SiO}_{2}}$ is obtained as

$$
\ln \left(\frac{\rho_{\mathrm{s}}-C_{\mathrm{SiO}_{2}}^{e}}{\rho_{\mathrm{s}}-C_{\mathrm{SiO}_{2}}}\right)=\ln \left(\frac{\rho_{\mathrm{s}}-C_{\mathrm{SiO}_{2}}^{e}}{\rho_{\mathrm{s}}-C_{\mathrm{SiO}_{2}}^{b}}\right) \cdot \frac{\ln \left(\frac{r}{r_{\mathrm{CaO}}}\right)}{\ln \left(\frac{r_{\mathrm{CaO}}^{0}}{r_{\mathrm{CaO}}}\right)} .
$$

Following the same procedure, the differential equation for the variation of $r_{\mathrm{CaO}}$ with $t$ comes as

$$
-r_{\mathrm{CaO}} \ln \left(\frac{r_{\mathrm{CaO}}^{0}}{r_{\mathrm{CaO}}}\right) \frac{\mathrm{d} r_{\mathrm{CaO}}}{\mathrm{d} t}=\frac{2 \rho_{\mathrm{s}} D_{\mathrm{p}} \ln \left(\frac{\rho_{\mathrm{s}}-C_{\mathrm{SiO}_{2}}^{e}}{\rho_{\mathrm{s}}-C_{\mathrm{SiO}_{2}}^{b}}\right)}{\rho_{\mathrm{CaO}}} .
$$

The integrated rate equation for product-layer diffusion control is then obtained as

$$
X+(1-X) \ln (1-X)=\frac{8 \rho_{\mathrm{s}} D_{\mathrm{p}} \ln \left(\frac{\rho_{\mathrm{s}}-C_{\mathrm{SO}_{2}}^{e}}{\rho_{\mathrm{s}}-C_{\mathrm{SiO}_{2}}^{b}}\right)}{\rho_{\mathrm{CaO}} r_{\mathrm{CaO}}^{0}} t .
$$

c. Interfacial reaction control. For the reaction,

$$
2 \mathrm{CaO}(\mathrm{s})+\left(\mathrm{SiO}_{2}\right)=2 \mathrm{CaO} \cdot \mathrm{SiO}_{2}(\mathrm{~s})
$$

assuming that the concentration of solids remain unchanged, the rate of reaction of $\mathrm{CaO}$ per unit area $\left(-v_{\mathrm{CaO}}\right)$ is given by

$$
\begin{aligned}
& -v_{\mathrm{CaO}}=k_{\mathrm{f}}^{\prime} C_{\mathrm{SiO}_{2}}^{b}-k_{\mathrm{b}}^{\prime}\left(\text { where } k_{\mathrm{f}}^{\prime}=k_{\mathrm{f}} C_{\mathrm{CaO}}^{2}\right. \\
& \text { and } \left.k_{b}^{\prime}=k_{b} C_{2 \mathrm{CaO} \cdot \mathrm{SiO}_{2}}\right) \text {. }
\end{aligned}
$$

At equilibrium, $-v_{\mathrm{CaO}}=0$ which gives

$$
\frac{k_{\mathrm{f}}^{\prime}}{k_{\mathrm{b}}^{\prime}}=\frac{1}{C_{\mathrm{SiO}_{2}}^{e}} \text {. }
$$

Substituting this in Eq. [15], we get

$$
-v_{\mathrm{CaO}}=k_{\mathrm{f}}^{\prime}\left[C_{\mathrm{SiO}_{2}}^{b}-C_{\mathrm{SiO}_{2}}^{e}\right] \text {. }
$$

Substituting $-v_{\mathrm{CaO}}$ with $n_{\mathrm{CaO}}$ and rewriting $n_{\mathrm{CaO}}$ in terms of $r_{\mathrm{CaO}}$, we get

$$
-\frac{\mathrm{d} r_{\mathrm{CaO}}}{\mathrm{d} t}=\frac{k_{\mathrm{f}}^{\prime}\left[C_{\mathrm{SiO}_{2}}^{b}-C_{\mathrm{SiO}_{2}}^{e}\right]}{\rho_{\mathrm{CaO}}} .
$$

The integrated rate equation for interfacial reaction control is then obtained as

$$
1-(1-X)^{\frac{1}{2}}=\frac{k_{\mathrm{f}}^{\prime}\left[C_{\mathrm{SiO}_{2}}^{b}-C_{\mathrm{SiO}_{2}}^{e}\right]}{\rho_{\mathrm{CaO}} r_{\mathrm{CaO}}^{0}} t .
$$

\section{Spherical specimen}

a. Slag-film diffusion control. Figure 4 gives a schematic representation of a spherical lime specimen in slag and the concentration profiles for slag-film diffusion control. A shell mass balance for $\mathrm{SiO}_{2}$ over a spherical shell of radius $r$ and thickness $\Delta r$ yields (when $\Delta r \rightarrow 0$ ):

$$
\frac{\mathrm{d}}{\mathrm{d} r}\left(r^{2} N_{\mathrm{SiO}_{2}(-r)}\right)=0 .
$$

Integrating Eq. [20] and following the same procedure as for a cylinder, we get

$$
\frac{1}{\left(\rho_{\mathrm{s}}-C_{\mathrm{SiO}_{2}}\right)} \cdot \frac{\mathrm{d} C_{\mathrm{SiO}_{2}}}{\mathrm{~d} r}=\frac{C_{3}}{r^{2}} .
$$

Integrating Eq. [21] with the same boundary conditions as Eq. [5], we get

$$
\ln \left(\frac{\rho_{\mathrm{s}}-C_{\mathrm{SiO}_{2}}^{e}}{\rho_{\mathrm{s}}-C_{\mathrm{SiO}_{2}}}\right)=\ln \left(\frac{\rho_{\mathrm{s}}-C_{\mathrm{SiO}_{2}}^{e}}{\rho_{\mathrm{s}}-C_{\mathrm{SiO}_{2}}^{b}}\right) \cdot \ln \left(\frac{\frac{1}{r_{\mathrm{CaO}}^{a}}-\frac{1}{r}}{\frac{1}{r_{\mathrm{CaO}}^{0}}-\frac{1}{r_{\mathrm{CaO}}^{0}+\delta_{\mathrm{C}}}}\right) .
$$




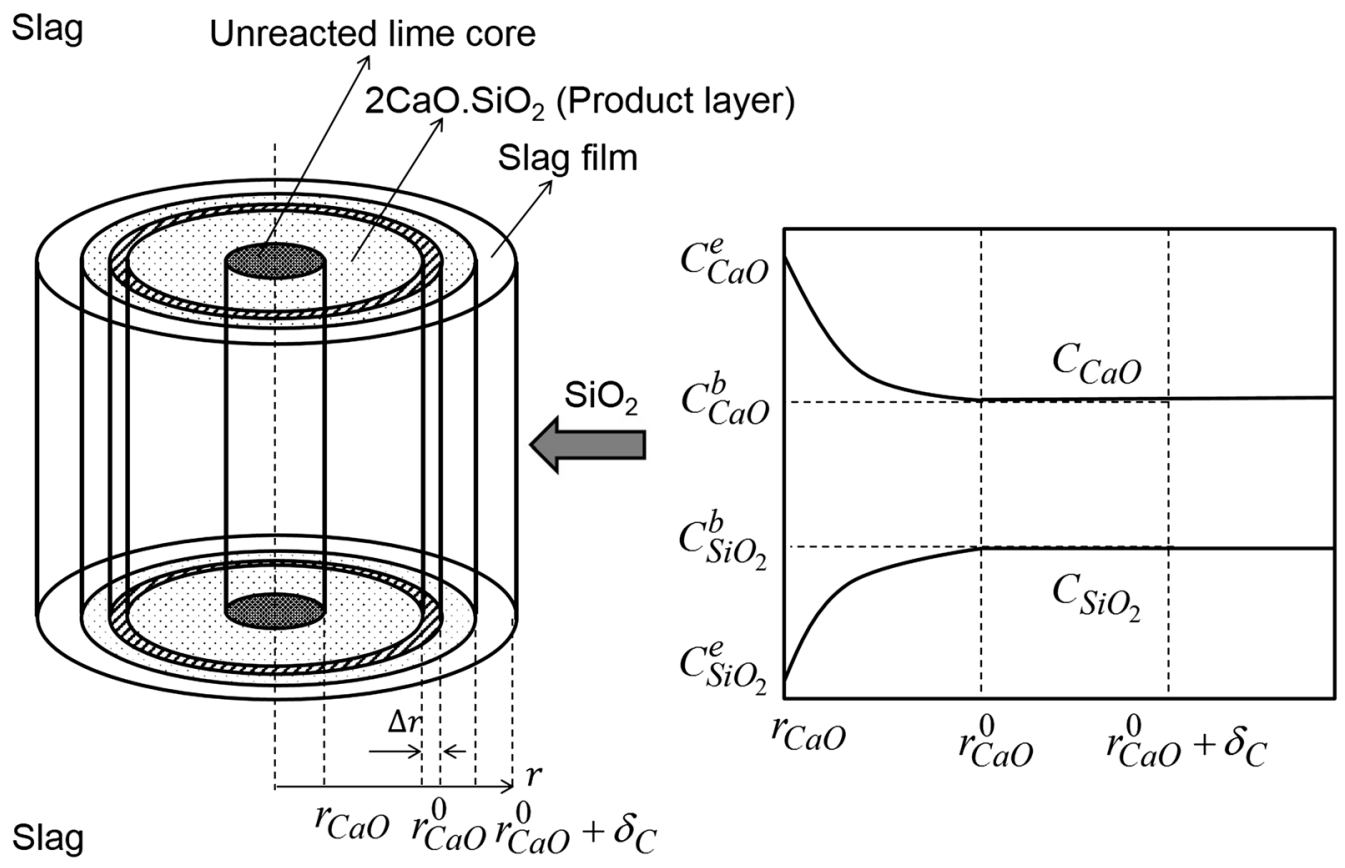

Fig. 3- Shell mass balance for a cylindrical $\mathrm{CaO}$ particle in slag and schematic concentration profiles for product-layer diffusion control.

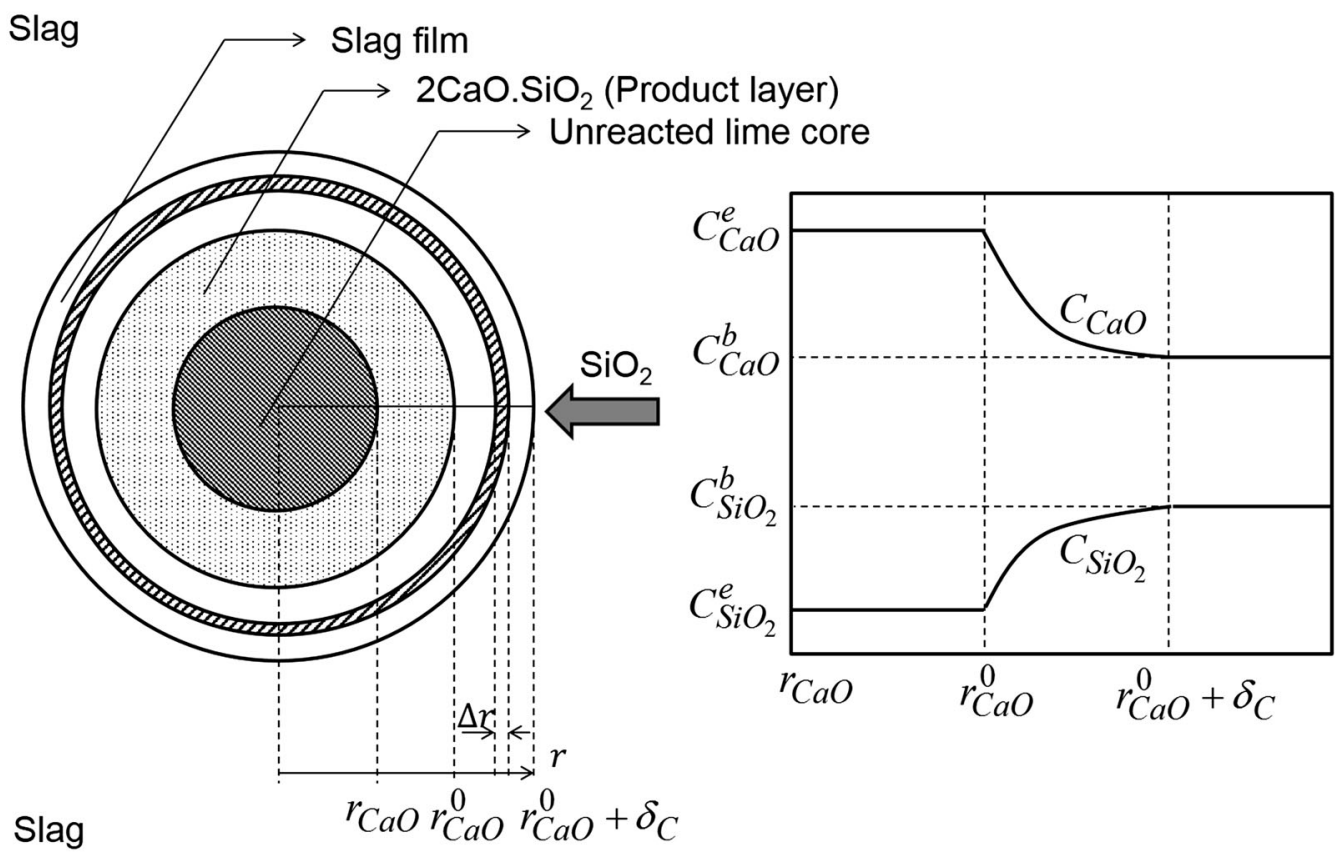

Fig. 4-Shell mass balance for a spherical $\mathrm{CaO}$ particle in slag and schematic concentration profiles for slag-film diffusion control.

$$
\left.W_{\mathrm{SiO}_{2}(-r)}\right|_{r}=\left.4 \pi r^{2} \cdot N_{\mathrm{SiO}_{2}(-r)}\right|_{r}=\frac{4 \pi \rho_{\mathrm{s}} D_{\mathrm{s}} \ln \left(\frac{\rho_{s}-C_{\mathrm{SiO}_{2}}^{e}}{\rho_{s}-C_{\mathrm{SiO}_{2}}^{b}}\right)}{\left(\frac{1}{r_{\mathrm{CaO}}^{0}}-\frac{1}{r_{\mathrm{CaO}}^{0}+\delta_{\mathrm{C}}}\right)} .
$$

The equation for the variation of $r_{\mathrm{CaO}}$ with $t$ as is obtained using the same method as

$$
-r_{\mathrm{CaO}}^{2} \frac{\mathrm{d} r_{\mathrm{CaO}}}{\mathrm{d} t}=\frac{2 \rho_{\mathrm{s}} D_{\mathrm{s}} \ln \left(\frac{\rho_{s}-C_{\mathrm{SiO}_{2}}^{e}}{\rho_{s}-C_{\mathrm{SiO}_{2}}^{b}}\right)}{\rho_{\mathrm{CaO}}\left(\frac{1}{r_{\mathrm{CaO}}^{0}}-\frac{1}{r_{\mathrm{CaO}}^{0}+\delta_{\mathrm{C}}}\right)} .
$$

The integrated form of rate equation for slag-film diffusion control is then obtained as 


$$
X=\frac{6 \rho_{\mathrm{s}} D_{\mathrm{s}} \ln \left(\frac{\rho_{\mathrm{s}}-C_{\mathrm{SiO}_{2}}^{e}}{\rho_{\mathrm{s}}-C_{\mathrm{SiO}_{2}}^{b}}\right)}{\rho_{\mathrm{CaO}}\left(\frac{1}{r_{\mathrm{CaO}}^{0}}-\frac{1}{r_{\mathrm{CaO}}^{0}+\delta_{\mathrm{C}}}\right) r_{\mathrm{CaO}}^{0}} t .
$$

b. Product-layer diffusion control. Figure 5 gives a schematic representation of the concentration profile for a spherical lime specimen when the diffusion through the product $\left(2 \mathrm{CaO} \cdot \mathrm{SiO}_{2}\right)$ layer is rate controlling. Performing a shell mass balance in the product layer and integrating with the boundary conditions of Eq. [11], the concentration profile for $C_{\mathrm{SiO}_{2}}$ is obtained as

$$
\ln \left(\frac{\rho_{\mathrm{s}}-C_{\mathrm{SiO}_{2}}^{e}}{\rho_{\mathrm{s}}-C_{\mathrm{SiO}_{2}}}\right)=\ln \left(\frac{\rho_{\mathrm{s}}-C_{\mathrm{SiO}_{2}}^{e}}{\rho_{\mathrm{s}}-C_{\mathrm{SiO}_{2}}^{b}}\right) \cdot \ln \left(\frac{\frac{1}{r_{\mathrm{CaO}}}-\frac{1}{r}}{\frac{1}{r_{\mathrm{CaO}}}-\frac{1}{r_{\mathrm{CaO}}^{0}}}\right) .
$$

The differential equation for the variation of $r_{\mathrm{CaO}}$ with $t$ and the integrated rate equation are then obtained, respectively, as

$$
\begin{gathered}
-r_{\mathrm{CaO}}^{2} \frac{\mathrm{d} r_{\mathrm{CaO}}}{\mathrm{d} t}=\frac{2 \rho_{\mathrm{s}} D_{\mathrm{s}} \ln \left(\frac{\rho_{\mathrm{s}}-C_{\mathrm{SiO}_{2}}^{e}}{\rho_{\mathrm{s}}-C_{\mathrm{SiO}_{2}}^{b}}\right)}{\rho_{\mathrm{CaO}}\left(\frac{1}{r_{\mathrm{CaO}}}-\frac{1}{r_{\mathrm{CaO}}^{0}}\right)} . \\
1-\frac{2}{3} X-(1-X)^{\frac{2}{3}}=\frac{4 \rho_{\mathrm{s}} D_{\mathrm{s}} \ln \left(\frac{\rho_{\mathrm{s}}-C_{\mathrm{SiO}_{2}}^{e}}{\rho_{\mathrm{s}}-C_{\mathrm{SiO}_{2}}^{b}}\right)}{\rho_{\mathrm{CaO}} r_{\mathrm{CaO}}^{0}{ }^{2}} t .
\end{gathered}
$$

c. Interfacial reaction control. To obtain the rate equations for interfacial reaction control, we make use of Eq. [17] and then replace $-v_{\mathrm{CaO}}$ in terms of $r_{\mathrm{CaO}}$ for a spherical geometry. Using the same method as before, the differential form of rate equation obtained is the same as Eq. [18], and the integrated rate equation is derived as

$$
1-(1-X)^{\frac{1}{3}}=\frac{k_{\mathrm{f}}^{\prime}\left[C_{\mathrm{SiO}_{2}}^{b}-C_{\mathrm{SiO}_{2}}^{e}\right]}{\rho_{\mathrm{CaO}} r_{\mathrm{CaO}}^{0}} t .
$$

\section{Rectangular specimen}

a. Slag-film diffusion control. Considering a rectangular shell having dimensions $\Delta l, w$ and $b$ (Figure 6) and a performing shell mass balance for the species $\mathrm{SiO}_{2}$ over this rectangular shell, we get

$$
\frac{\mathrm{d}}{\mathrm{d} l}\left(N_{\mathrm{SiO}_{2}(-l)}\right)=0 \text {. }
$$

The differential equation for the variation of $C_{\mathrm{SiO}_{2}}$ with $l$ is then obtained as

$$
\frac{1}{\left(\rho_{\mathrm{s}}-C_{\mathrm{SiO}_{2}}\right)} \cdot \frac{\mathrm{d} C_{\mathrm{SiO}_{2}}}{\mathrm{~d} l}=C_{6}
$$

Integrating Eq. [31] with the boundary conditions

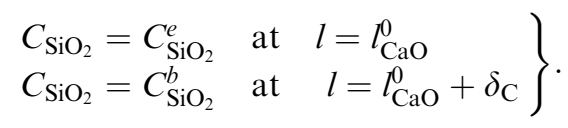

The concentration profile for $C_{\mathrm{SiO}_{2}}$ is obtained as

$$
\ln \left(\frac{\rho_{\mathrm{s}}-C_{\mathrm{SiO}_{2}}^{e}}{\rho_{\mathrm{s}}-C_{\mathrm{SiO}_{2}}}\right)=\ln \left(\frac{\rho_{\mathrm{s}}-C_{\mathrm{SiO}_{2}}^{e}}{\rho_{\mathrm{s}}-C_{\mathrm{SiO}_{2}}^{b}}\right) \cdot\left(\frac{l-l_{\mathrm{CaO}}^{0}}{\delta_{\mathrm{C}}}\right) .
$$

The molar rate of diffusion at is given by

$$
\left.W_{\mathrm{SiO}_{2}(-l)}\right|_{l}=\left.w b N_{\mathrm{SiO}_{2}(-l)}\right|_{l}=\frac{w b \rho_{\mathrm{s}} D_{\mathrm{s}}}{\delta_{\mathrm{C}}} \cdot \ln \left(\frac{\rho_{\mathrm{s}}-C_{\mathrm{SiO}_{2}}^{e}}{\rho_{\mathrm{s}}-C_{\mathrm{SiO}_{2}}^{b}}\right) \text {. }
$$

The differential form of the rate equation is obtained likewise as

$$
-\frac{\mathrm{d} l_{\mathrm{CaO}}}{\mathrm{d} t}=\frac{2 \rho_{\mathrm{s}} D_{\mathrm{s}} \ln \left(\frac{\rho_{\mathrm{s}}-C_{\mathrm{Si}_{2}}^{e}}{\rho_{\mathrm{s}}-C_{\mathrm{SiO}_{2}}^{b}}\right)}{\rho_{\mathrm{CaO}} \delta_{\mathrm{C}}},
$$

and the integrated rate equation for slag-film diffusion control is given by

$$
X=\frac{2 \rho_{\mathrm{s}} D_{\mathrm{s}} \ln \left(\frac{\rho_{\mathrm{s}}-C_{\mathrm{SiO}_{2}}^{e}}{\rho_{\mathrm{s}}-C_{\mathrm{SiO}_{2}}}\right)}{\rho_{\mathrm{CaO}} \delta_{\mathrm{C}} l_{\mathrm{CaO}}^{0}} t .
$$

b. Product-layer diffusion control. Considering a shell having dimensions $\Delta l, w$ and $b$ in the product layer (Figure 7) and following the same procedure as above, an equation similar to Eq. [31] is obtained. Now integrating with the boundary conditions

$$
\left.\begin{array}{lll}
C_{\mathrm{SiO}_{2}}=C_{\mathrm{SiO}_{2}}^{e} & \text { at } & l=l_{\mathrm{CaO}} \\
C_{\mathrm{SiO}_{2}}=C_{\mathrm{SiO}_{2}}^{b} & \text { at } & l=l_{\mathrm{CaO}}^{0}
\end{array}\right\} .
$$

The concentration profile for $\mathrm{SiO}_{2}$ is obtained as

$$
\ln \left(\frac{\rho_{\mathrm{s}}-C_{\mathrm{SiO}_{2}}^{e}}{\rho_{\mathrm{s}}-C_{\mathrm{SiO}_{2}}}\right)=\ln \left(\frac{\rho_{\mathrm{s}}-C_{\mathrm{SiO}_{2}}^{e}}{\rho_{\mathrm{s}}-C_{\mathrm{SiO}_{2}}^{b}}\right) \cdot\left(\frac{l-l_{\mathrm{CaO}}}{l_{\mathrm{CaO}}^{0}-l_{\mathrm{CaO}}}\right) .
$$

Following the same procedure as before, the differential and integrated forms of rate equations are obtained, respectively, as

$$
-\left(l_{\mathrm{CaO}}^{0}-l_{\mathrm{CaO}}\right) \frac{\mathrm{d} l_{\mathrm{CaO}}}{\mathrm{d} t}=\frac{2 \rho_{\mathrm{s}} D_{\mathrm{p}} \ln \left(\frac{\rho_{\mathrm{s}}-C_{\mathrm{SiO}_{2}}^{e}}{\rho_{\mathrm{s}}-C_{\mathrm{SiO}_{2}}^{b}}\right)}{\rho_{\mathrm{CaO}}} .
$$

$$
X^{2}=\frac{4 \rho_{\mathrm{s}} D_{\mathrm{p}} \ln \left(\frac{\rho_{\mathrm{s}}-C_{\mathrm{SiO}_{2}}^{e}}{\rho_{\mathrm{s}}-C_{\mathrm{Si}_{2}}^{b}}\right)}{\rho_{\mathrm{CaO}} l_{\mathrm{CaO}}^{20}} t .
$$




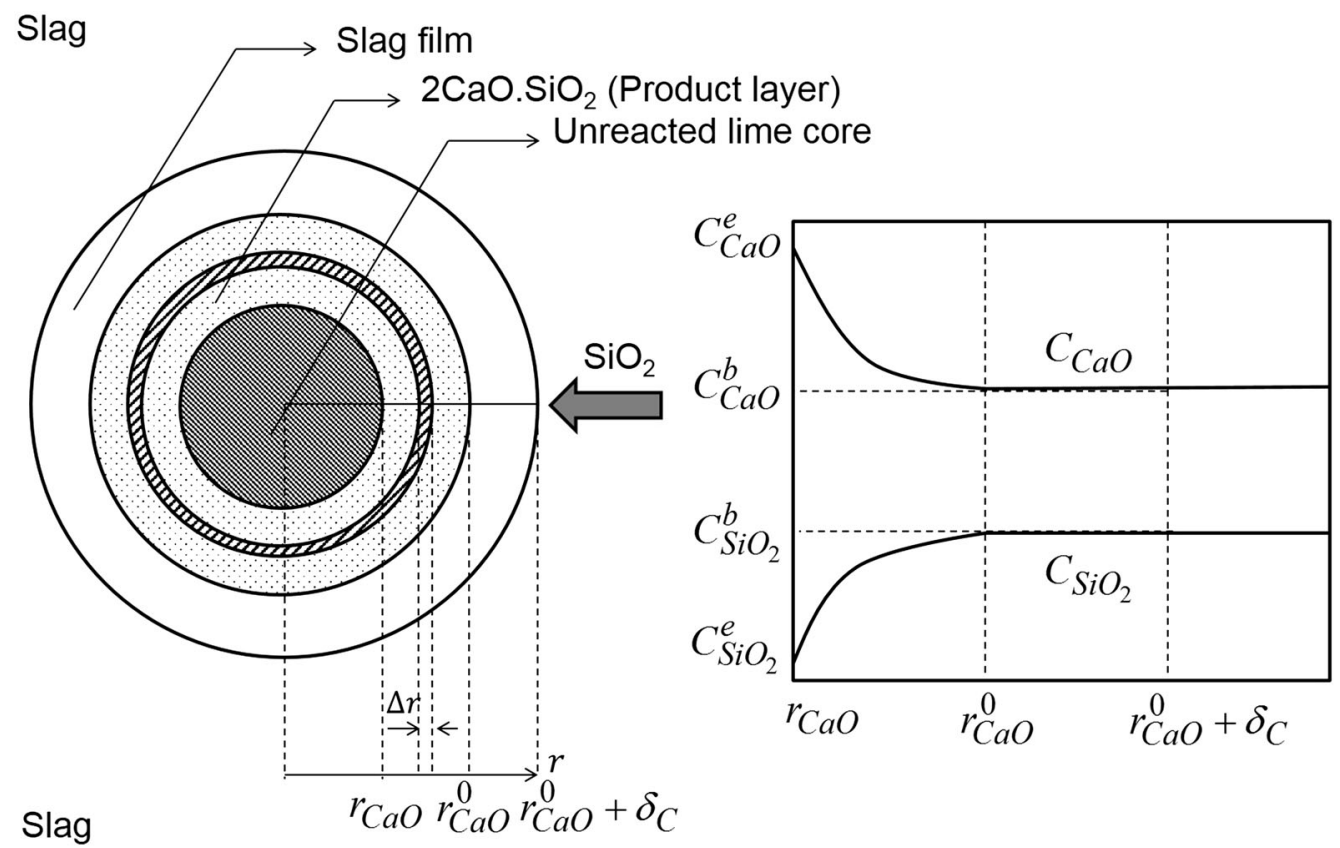

Fig. 5-Shell mass balance for a spherical $\mathrm{CaO}$ particle in slag and schematic concentration profiles for product-layer diffusion control.
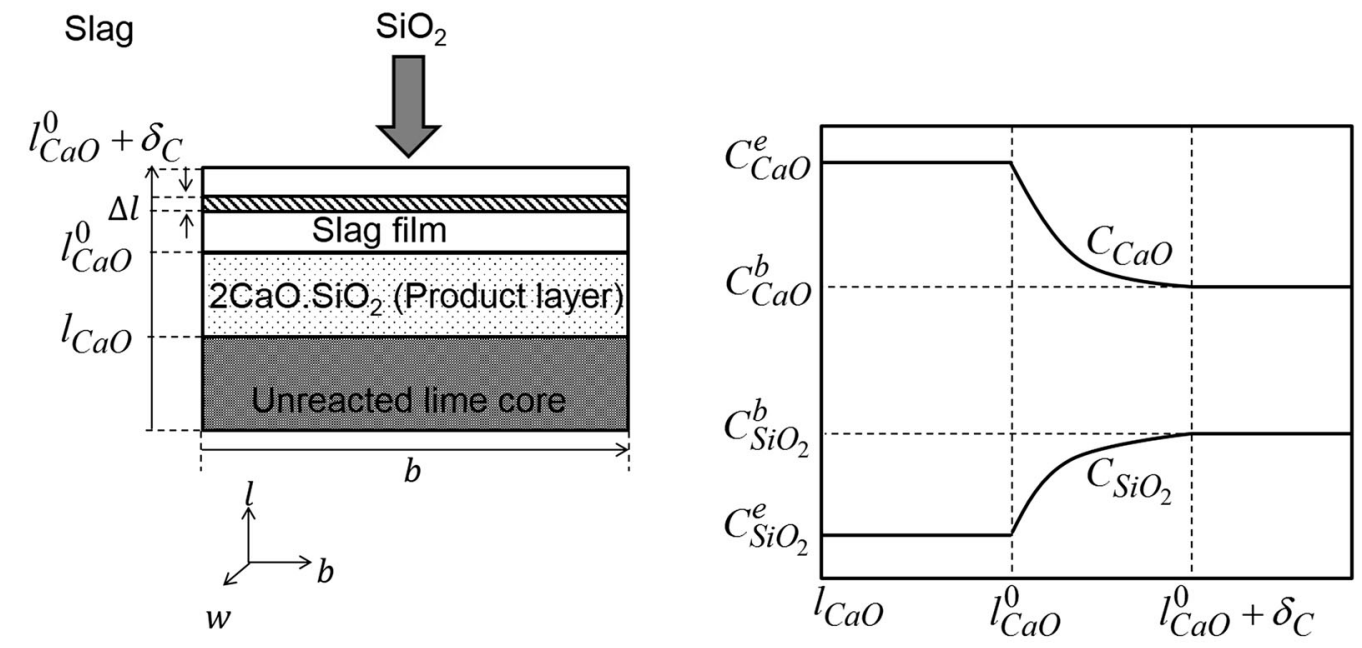

Slag

Fig. 6- Shell mass balance for a rectangular $\mathrm{CaO}$ particle in slag and schematic concentration profiles for slag-film diffusion control.

c. Interfacial control. Using Eq. [17] and substituting $-v_{\mathrm{CaO}}$ in terms of $w, b, l_{\mathrm{CaO}}$ for rectangular geometry, differential and integrated rate laws for interfacial reaction control are obtained, respectively, as

$$
\begin{gathered}
-\frac{\mathrm{d} l_{\mathrm{CaO}}}{\mathrm{d} t}=\frac{k_{\mathrm{f}}^{\prime}\left[C_{\mathrm{SiO}_{2}}^{b}-C_{\mathrm{SiO}_{2}}^{e}\right]}{\rho_{\mathrm{CaO}}} . \\
X=\frac{k_{\mathrm{f}}^{\prime}\left[C_{\mathrm{SiO}_{2}}^{b}-C_{\left.\mathrm{SiO}_{2}\right]}^{e} t .\right.}{\rho_{\mathrm{CaO}} l_{\mathrm{CaO}}^{0}} .
\end{gathered}
$$

A summary of integrated rate equations for different geometries of lime specimen and for different controlling mechanisms is given in Table I.

\section{Mixed control model for lime dissolution}

a. Cylindrical specimen. Using the differential and integrated forms of rate equations for the three different controls and following the general procedure used for deriving mixed control equations, ${ }^{[16]}$ the differential and integrated rate equations for mixed control kinetics are obtained, respectively, as 


$$
\begin{gathered}
-\frac{\mathrm{d} r_{\mathrm{CaO}}}{\mathrm{d} t}\left(\frac{r_{\mathrm{CaO}} \ln \left(\frac{r_{\mathrm{CaO}}^{0}+\delta_{\mathrm{C}}}{r_{\mathrm{CaO}}^{0}}\right)}{2 \rho_{\mathrm{s}} D_{\mathrm{s}}}+\frac{r_{\mathrm{CaO}} \ln \left(\frac{r_{\mathrm{CaO}}^{0}}{r_{\mathrm{CaO}}}\right)}{2 \rho_{\mathrm{s}} D_{\mathrm{p}}}\right. \\
\left.+\frac{1}{k_{\mathrm{f}}^{\prime}\left[C_{\mathrm{SiO}_{2}}^{p}-C_{\mathrm{SiO}_{2}}^{e}\right]}\right)=\frac{1+\ln \left(\frac{\rho_{\mathrm{s}}-C_{\mathrm{SiO}_{2}}^{e}}{\rho_{\mathrm{s}}-C_{\mathrm{SiO}_{2}}^{b}}\right)}{\rho_{\mathrm{CaO}}} \\
\left(\frac{r_{\mathrm{CaO}}^{0} \ln \left(\frac{r_{\mathrm{CaO}}^{0}+\delta_{\mathrm{C}}}{r_{\mathrm{CaO}}^{0}}\right)}{4 \rho_{\mathrm{s}} D_{\mathrm{s}}} X+\frac{r_{\mathrm{CaO}}^{0}}{8 \rho_{\mathrm{s}} D_{\mathrm{p}}}(X+(1-X) \ln (1-X))\right. \\
\left.+\frac{1-(1-X)^{\frac{1}{2}}}{k_{\mathrm{f}}^{\prime}\left[C_{\mathrm{SiO}_{2}}^{p}-C_{\mathrm{SiO}_{2}}^{e}\right.}\right)=\frac{1+\ln \left(\frac{\rho_{\mathrm{s}}-C_{\mathrm{SiO}_{2}}^{e}}{\rho_{\mathrm{s}}-C_{\mathrm{SiO}_{2}}^{b}}\right)}{\rho_{\mathrm{CaO}} r_{\mathrm{CaO}}^{0}} t .
\end{gathered}
$$

b. Spherical specimen. Differential and integrated rate laws for a spherical lime specimen are obtained likewise as

$$
\begin{gathered}
-\frac{\mathrm{d} r_{\mathrm{CaO}}}{\mathrm{d} t}\left(\frac{r_{\mathrm{CaO}}^{2}\left(\frac{1}{r_{\mathrm{CaO}}^{0}}-\frac{1}{r_{\mathrm{CaO}}^{0}+\delta_{\mathrm{C}}}\right)}{2 \rho_{\mathrm{s}} D_{\mathrm{s}}}+\frac{r_{\mathrm{CaO}}^{2}\left(\frac{1}{r_{\mathrm{CaO}}}-\frac{1}{r_{\mathrm{CaO}}^{0}}\right)}{2 \rho_{s} D_{p}}\right. \\
\left.+\frac{1}{k_{\mathrm{f}}^{\prime}\left[C_{\mathrm{SiO}_{2}}^{p}-C_{\mathrm{SiO}_{2}}^{e}\right]}\right)=\frac{1+\ln \left(\frac{\rho_{\mathrm{s}}-C_{\mathrm{SiO}_{2}}^{e}}{\rho_{\mathrm{s}}-C_{\mathrm{SiO}_{2}}^{b}}\right)}{\rho_{\mathrm{CaO}}} . \\
\left(\frac{\delta_{\mathrm{C}}}{6 \rho_{\mathrm{s}} D_{\mathrm{s}}} X+\frac{r_{\mathrm{CaO}}^{0}}{12 \rho_{\mathrm{s}} D_{\mathrm{p}}}\left(3-3(1-X)^{\left.\frac{2}{3}-2 X\right)}\right.\right. \\
\left.+\frac{1-(1-X)^{\frac{1}{3}}}{k_{\mathrm{f}}^{\prime}\left[C_{\mathrm{SiO}_{2}}^{p}-C_{\mathrm{SiO}_{2}}^{e}\right.}\right)=\frac{1+\ln \left(\frac{\rho_{\mathrm{s}}-C_{\mathrm{SiO}_{2}}^{e}}{\rho_{\mathrm{s}}-C_{\mathrm{SiO}_{2}}^{b}}\right)}{\rho_{\mathrm{CaO}} r_{\mathrm{CaO}}^{0}} t .
\end{gathered}
$$

c. Rectangular specimen. Differential and integrated rate laws for a cube lime specimen are obtained likewise as

$$
\begin{aligned}
& -\frac{\mathrm{d} l_{\mathrm{CaO}}}{\mathrm{d} t}\left(\frac{\delta_{\mathrm{C}}}{2 \rho_{\mathrm{s}} D_{\mathrm{s}}}+\frac{\left(l_{\mathrm{CaO}}^{0}-l_{\mathrm{CaO}}\right)}{2 \rho_{\mathrm{s}} D_{\mathrm{p}}}+\frac{1}{k_{\mathrm{f}}^{\prime}\left[C_{\mathrm{SiO}_{2}}^{p}-C_{\mathrm{SiO}_{2}}^{e}\right]}\right) \\
& =\frac{1+\ln \left(\frac{\rho_{\mathrm{s}}-C_{\mathrm{SiO}_{2}}^{e}}{\rho_{\mathrm{s}}-C_{\mathrm{SiO}_{2}}^{b}}\right)}{\rho_{\mathrm{CaO}}} . \\
& \left(\frac{\delta_{\mathrm{C}}}{2 \rho_{\mathrm{s}} D_{\mathrm{s}}} X+\frac{l_{\mathrm{CaO}}^{0}}{4 \rho_{\mathrm{s}} D_{\mathrm{p}}} X^{2}+\frac{X}{k_{\mathrm{f}}^{\prime}\left[C_{\mathrm{SiO}_{2}}^{p}-C_{\mathrm{SiO}_{2}}^{e}\right]}\right) \\
& =\frac{1+\ln \left(\frac{\rho_{\mathrm{s}}-C_{\mathrm{SiO}_{2}}^{e}}{\rho_{\mathrm{s}}-C_{\mathrm{SiO}_{2}}^{b}}\right)}{\rho_{\mathrm{CaO}} l_{\mathrm{CaO}}^{0}} t .
\end{aligned}
$$

5. Calculation of concentration boundary layer thickness $\left(\delta_{C}\right)$

Rate equations developed in the preceding sections necessitate the estimation of $\delta_{\mathrm{C}}$. Kosaka et al. ${ }^{[17]}$ empirically expressed $\delta_{\mathrm{C}}$ as a function of slag properties, and the speed of revolution for the dissolution of a rotating steel cylinder into liquid zinc or aluminum as

$$
\delta_{\mathrm{C}}=4.76 \cdot d_{\mathrm{CaO}}^{1.5} \cdot \mathrm{Re}^{-0.62} \cdot \mathrm{Sc}^{-0.35} .
$$

In the absence of any suitable correlation for calculating $\delta_{C}$, in the case of lime dissolution in steelmaking slags, Eq. [49] is used to estimate $\delta_{\mathrm{C}}$. A correction factor $\alpha$ is then used so that reasonable agreement between the model predictions and experimental results is achieved.

\section{Temperature dependence of diffusivity $\left(D_{S}\right)$ and} viscosity $(\eta)$

In the proposed model, effects of temperature on $D_{\mathrm{s}}$ (and $D_{\mathrm{p}}$ ) and $\eta$ are modeled by assuming that they exhibit an Arrhenius type of relationship with temperature, respectively, as follows:

$$
\begin{gathered}
D_{\mathrm{s}}=D_{0} \exp \left(\frac{-E_{\mathrm{S}}}{R T}\right) . \\
\eta=\eta_{0} \exp \left(\frac{E_{\eta}}{R T}\right) .
\end{gathered}
$$

7. Estimation of activity coefficient of $\mathrm{SiO}_{2}\left(\gamma_{\mathrm{SiO}_{2}}\right)$.

To estimate $\gamma_{\mathrm{SiO}_{2}}$ as a function of slag composition and temperature, a large number of thermodynamic calculations are carried out using Equilib module of FactSage Version $6.4^{[18]}$ at various slag compositions and temperatures (relevant to steelmaking operations). Finally, the thermodynamic data have been curve-fitted to obtain an equation for predicting $\gamma_{\mathrm{SiO}_{2}}$ as a function of slag composition and temperature. In the ranges studied, analyses yield

$$
\begin{aligned}
\log \gamma_{\mathrm{SiO}_{2}}= & -1.1414-4.0259 x_{\mathrm{CaO}}+10.8373 x_{\mathrm{SiO}_{2}} \\
& +4.5569 x_{\mathrm{FeO}}-\frac{5243.4}{T}\left(R^{2}=0.99\right) .
\end{aligned}
$$

\section{Solution Strategy}

Computational study for the present model has been carried out using MATLAB ${ }^{\circledR}$ Version R2009a.Algebraic and transcendental equations are solved using the Newton-Raphson method. An under-relaxation parameter $(\beta)$ is used wherever necessary, and its value has been chosen by reaching a compromise between accuracy in calculations and computational speed.

For validating the model with experimental data of other researchers, ${ }^{[4,7,10]}$ rate equations for different geometries are solved with input conditions similar to those mentioned in the relevant literature. When this model is applied as a submodel to the global model for 

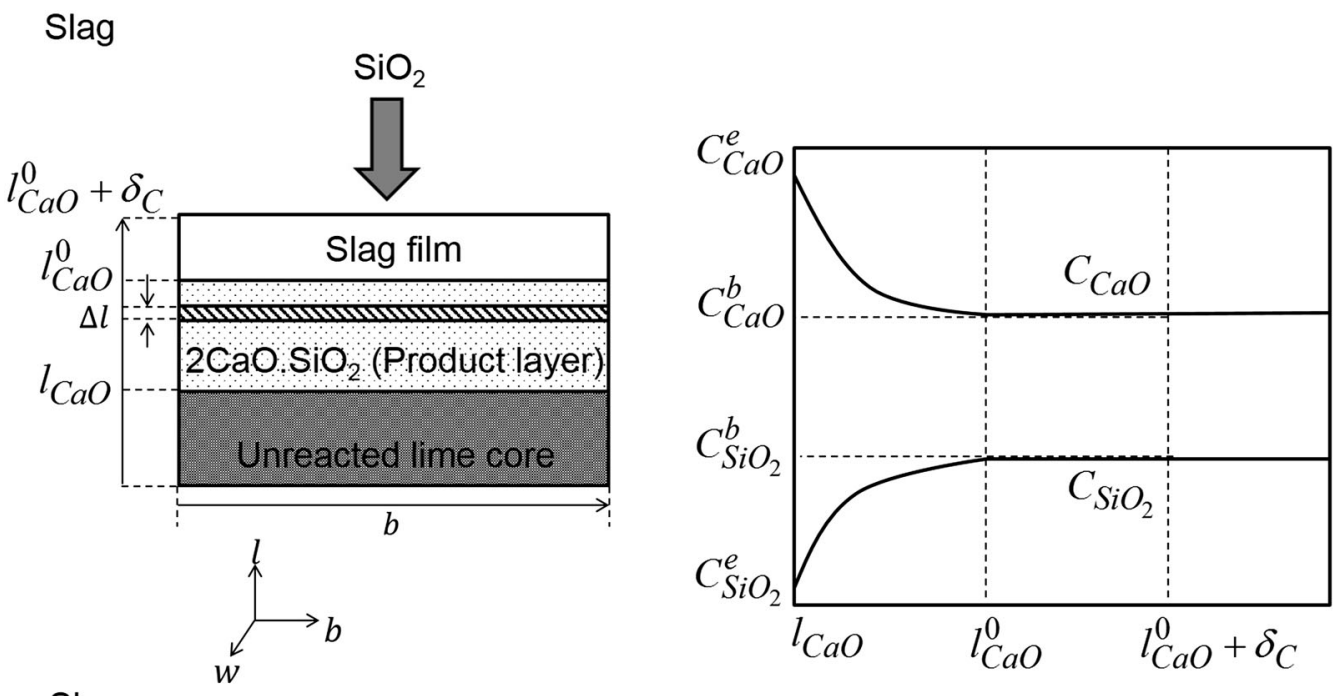

Slag

Fig. 7-Shell mass balance for a rectangular $\mathrm{CaO}$ particle in slag and schematic concentration profiles for product-layer diffusion control.

Table I. Summary of Integrated Forms of Rate Equations for Different Geometries and Rate-Controlling Mechanisms

\begin{tabular}{lccc}
\hline & Slag-Film Diffusion & Product-Layer Diffusion & Interfacial Reaction \\
\hline Cylindrical & $X=k_{1} t$ & $X+(1-X) \ln (1-X)=k_{2} t$ & $1-(1-X)_{1}^{\frac{1}{2}}=k_{3} t$ \\
Spherical & $X=k_{4} t$ & $1-\frac{2}{3} X-(1-X)^{\frac{2}{3}}=k_{5} t$ & $1-(1-X)^{\frac{1}{3}}=k_{6} t$ \\
Rectangular & $X=k_{7} t$ & $X^{2}=k_{8} t$ & $X=k_{9} t$ \\
\hline
\end{tabular}

LD steelmaking, the pertinent equations are solved with input conditions already published in the previous study $^{[1]}$ and hence not repeated here. Only, the list of new model variables used in the submodel for lime dissolution is mentioned in Table II. A new lance height practice is applied in the current study for better agreement with plant measurements ${ }^{[2]}$ and has also been mentioned in Table II. The thermodynamic data required for model calculations are obtained from one of the standard data-sources. ${ }^{[19]}$ Diffusivity of silica in slags is obtained from typical values reported by Dolan et $a l^{[20]}$ and the values of $E_{\mathrm{S}}$ and $E_{\eta}$ are obtained from Matsushima et al. ${ }^{[4]}$ In the absence of experimental data on $D_{\mathrm{p}}$, simulation studies are carried out for different values of $\varphi$ (the ratio between $D_{\mathrm{p}}$ and $D_{\mathrm{s}}$ ). A value of $\varphi=0.5$ gives a reasonably good agreement between model predictions and the observed values.

\section{RESULTS AND DISCUSSIONS}

In this section, the results of the solutions of rate equations for mixed control (Eqs. [43] through [48]) are discussed and compared with experimental data published elsewhere. ${ }^{[4,7,10]}$ In addition, the effects of process variables on lime dissolution rate have been identified and also compared with experimental results, whatsoever available. ${ }^{[4,9]}$ Finally, this model is incorporated as a submodel in the global model ${ }^{[1]}$ for calculating lime dissolution rates during actual blowing conditions. With the lime dissolution submodel incorporated, the predictions for slag compositions have been discussed, and improvements vis-a-vis the previous model have been analyzed.

\section{A. Dissolution Rates for Different Lime Geometries}

\section{Cylindrical specimen}

To calculate the rate of dissolution for a cylindrical lime specimen, Eq. [44] is solved to obtain the fractional conversion of lime $(X)$ at various times. The results are plotted in Figure 8 and compared with the experimental results published by Matsushima et al. ${ }^{[4]}$ for different speeds of revolution of the rotating lime specimen. As evident from Figure 8, model predictions for $r_{\mathrm{CaO}}$ show good agreement with the experimental values. The model predicts the right trend in $X v s t$ plots for all different speeds of revolutions, and the agreement with experimental data is increasingly prominent for higher speeds of revolution. At 300 and $400 \mathrm{rpm}$, model predictions match excellently with the experimental results. At 200 and $100 \mathrm{rpm}$, predictions are relatively poor although the model still predicts the right trends. A possible reason for the relatively poor agreement at low rpms (especially for $\mathrm{rpm}=100$ ) might be the error involved in calculating $\delta_{\mathrm{C}}$ using Eq. [49]. At low rpms, values of $\delta_{\mathrm{C}}$ are expected to be very high resulting in much slower rates of diffusion through the slag-film. Under such conditions slag-film diffusion may be rate controlling. However, when $\delta_{\mathrm{C}}$ is calculated using Eq. [49], it does not become sufficiently large at low 
Table II. List of Input Parameters used in the Lime Dissolution Submodel ${ }^{[4,20]}$

\begin{tabular}{|c|c|c|}
\hline Quantity & Unit & Value \\
\hline Lance height practice (as input to global model) & $\mathrm{m}$ & $2.6-2.45-2.30-2.05-1.75-1.25$ \\
\hline Initial radius of cylindrical lime particle & $\mathrm{m}$ & 0.015 \\
\hline Length of cylindrical lime particle & $\mathrm{m}$ & 0.03 \\
\hline $\begin{array}{l}\text { Modified forward reaction rate constant for the reaction of } \\
\mathrm{CaO} \text { with } \mathrm{SiO}_{2} \text { at } \mathrm{CaO}-2 \mathrm{CaO} \cdot \mathrm{SiO}_{2} \text { interface }\end{array}$ & $\mathrm{m} / \mathrm{s}$ & $1.0 \times 10^{4}$ \\
\hline Activation energy for $\mathrm{SiO}_{2}$ diffusion in slags ${ }^{[4]}$ & $\mathrm{KJ}$ & 294 \\
\hline Activation energy for viscous flow of slags ${ }^{[4]}$ & $\mathrm{KJ}$ & 210 \\
\hline Diffusivity of $\mathrm{SiO}_{2}$ in slag at $1773 \mathrm{~K}\left(1500^{\circ} \mathrm{C}\right)^{[20]}$ & $\mathrm{m}^{2} / \mathrm{s}$ & $2.0 \times 10^{-9}$ \\
\hline $\begin{array}{l}\text { Number of revolutions of the rotating lime cylinders (used for } \\
\text { calculating boundary layer thickness) }\end{array}$ & $\min ^{-1}$ & 400 \\
\hline Ratio of the diffusivities of $\mathrm{SiO}_{2}$ through $2 \mathrm{CaO} \cdot \mathrm{SiO}_{2}$ and slag & - & 0.5 \\
\hline Under relaxation parameter & - & 0.01 \\
\hline Correction factor for boundary layer calculation & - & 5 \\
\hline
\end{tabular}

rpms, and hence the model over-predicts the values of $X$ at lower speeds of revolutions.

\section{Spherical specimen}

Rates of dissolution for a spherical lime specimen have been calculated by solving Eq. [46] to obtain the fractional conversion of lime $(X)$ at various times. The results are plotted in Figure 9 and compared with the experimental data reported by Guo et al. ${ }^{10]}$ An analysis of the experimental data published by Guo et al. ${ }^{[10]}$ clearly shows three distinct regimes in $X$ vs $t$ plot. The authors argue that the formation of multisolid layer (assumed to $2 \mathrm{CaO} \cdot \mathrm{SiO}_{2}$ in the current study) starts after some period, reaches a particular thickness and then the layer gets completely dissolved. Such phenomena, however, are not considered in the model (which assumes that a layer of $2 \mathrm{CaO} \cdot \mathrm{SiO}_{2}$ is present always) and thus predictions do not necessary corroborate with the experimental results, especially during the initial regime. Predicted trend of $X$ vs $t$ plot shows only two distinct regimes: an initial period when $\delta_{\mathrm{C}}$ is high (since $r_{\mathrm{CaO}}$ is large) and slag-film diffusion is rate-controlling; and a final regime when $\delta_{\mathrm{C}}$ is low (because of smaller $r_{\mathrm{CaO}}$ ) and a mixed control mechanism of slag-film diffusion and product-layer diffusion govern the rate. In the later stages, there is a good correspondence between predicted and experimental values, although predictions for the initial periods have a greater deviation.

\section{Rectangular specimen}

For rectangular specimen Eq. [48] is solved to obtain $X$ at various times $(t)$. Results have been compared with the experimental data on lime dissolution for cubic specimens by Deng et al. ${ }^{[7]}$ and plotted in Figure 10. As evident from the model results for $X v s t$ plot, a mixed control mechanism of slag-film and product-layer diffusion determines the rate of dissolution. Experimental results also point toward such a mechanism, and a fairly good agreement is achieved between the model results and the experimental values during a major part of the time-period. Only toward the very late stages, the model predictions show some deviation from the experimental data. A possible source of error, as already explained, may be the inaccuracy in calculating $\delta_{\mathrm{C}}$. Also, the present model assumes diffusion to be occurring only along one direction. For a rectangular geometry, such an assumption holds true only if each of the other two directions is much larger than the direction of diffusion. However, Deng et al's. ${ }^{[7]}$ experimental data are for cubic specimens where all dimensions are equal and diffusion is expected to take place along all the three directions. Thus evidently, this approximation might have resulted in some errors in calculation.

\section{B. Effects of Process Variables on Dissolution Rate}

\section{Temperature}

Effects of temperature on dissolution rate have been modeled by taking into account its effect on the model variables. $C_{\mathrm{SiO}_{2}}^{e}\left(a_{\mathrm{SiO}_{2}}\right.$ and $\left.\gamma_{\mathrm{SiO}_{2}}\right), k_{\mathrm{f}}^{\prime}, \rho_{\mathrm{s}}, \rho_{\mathrm{CaO}}, D_{\mathrm{s}}$ (and also $\left.D_{\mathrm{p}}\right), \eta$ (and hence $\delta_{\mathrm{C}}$ ) are the model variables which vary with temperature. In the range of temperatures considered, $\rho_{\mathrm{s}}$ and $\rho_{\mathrm{CaO}}$ do not practically vary with temperature, and the effect of temperature on $k_{\mathrm{f}}^{\prime}$, although significant, is of no practical importance since interfacial reaction does not have much effect on the overall rate. Both $a_{\mathrm{SiO}_{2}}$ and $\gamma_{\mathrm{SiO}_{2}}$ increase with temperature thus counteracting the effect of temperature on $C_{\mathrm{SiO}_{2}}^{e}$ (which depends on the ratio between $a_{\mathrm{SiO}_{2}}$ and $\gamma_{\mathrm{SiO}_{2}}$ ). Still $C_{\mathrm{SiO}_{2}}^{e}$ marginally increases with temperature but that practically has no effect on dissolution rate which depends on the concentration difference $\left(\rho_{\mathrm{s}}-C_{\mathrm{SiO}_{2}}^{e}\right)$ and $\rho_{\mathrm{s}}$ is at least two orders of magnitude higher than $C_{\mathrm{SiO}_{2}}^{e}$. Thus $D_{\mathrm{s}}$ (and also $D_{\mathrm{p}}$ ) and $\eta$ (and hence $\delta_{\mathrm{C}}$ ) are the only variables which vary significantly with temperature. From Eq. [49], we get

$$
k_{\mathrm{m}} \propto D_{\mathrm{s}}^{0.7} \eta^{-0.32} \text {. }
$$

As evident from Eqs. [50] and [51], $D_{\mathrm{s}}$ exponentially increases and $\eta$ exponentially decreases with temperature, both of which increase $k_{\mathrm{m}}$. $D_{\mathrm{p}}$ (assumed to be $0.5 D_{\mathrm{s}}$ ) also increases exponentially with temperature, and hence lime dissolution rates increase significantly with temperature. In fact, lime dissolution rate also follow an Arrhenius relationship with temperature as illustrated in Figure 11. For an increase in temperature by $50 \mathrm{~K}\left(50{ }^{\circ} \mathrm{C}\right)$ from $1773 \mathrm{~K}$ to $1823 \mathrm{~K}\left(1500{ }^{\circ} \mathrm{C}\right.$ to $1550{ }^{\circ} \mathrm{C}$ ) the dissolution rate becomes almost twice its 


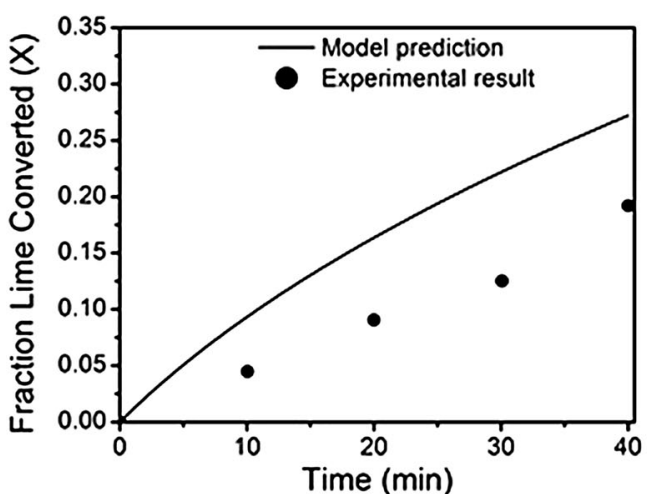

(a)

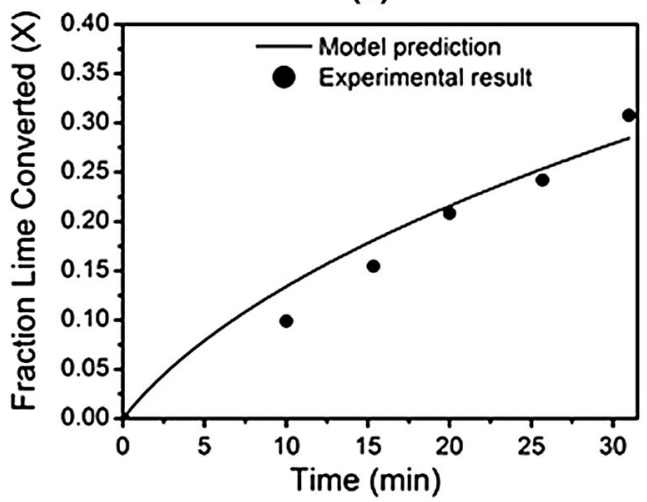

(c)

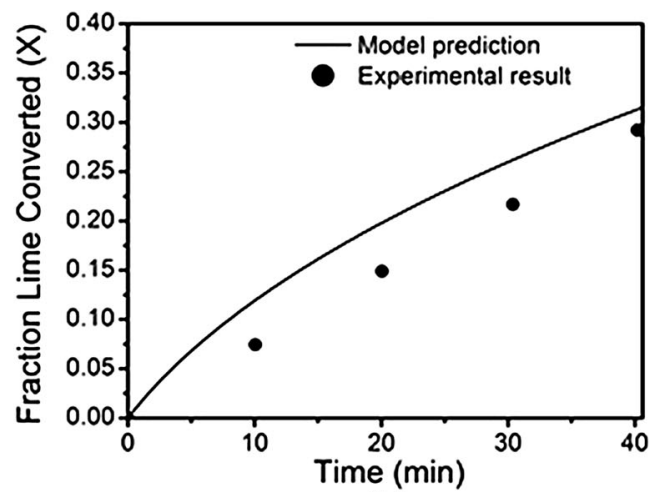

(b)

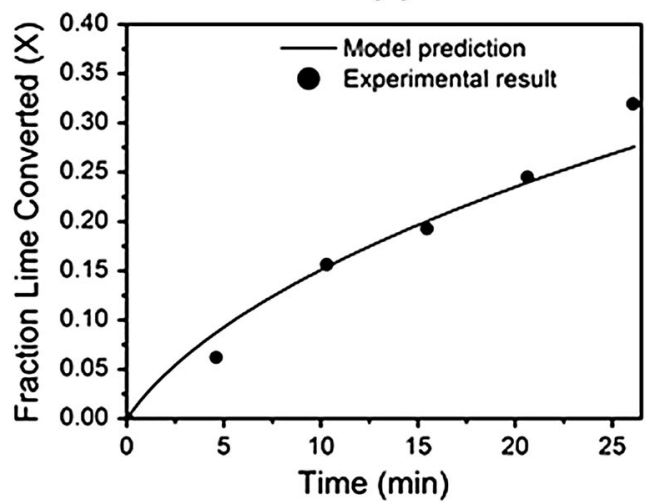

(d)

Fig. 8-Model predictions of fractional conversion of $\mathrm{CaO}(X)$ for a rotating cylindrical specimen compared with the experimental data of Matsushima et al.: ${ }^{[4]}$ (a) $100 \mathrm{rpm},(b) 200 \mathrm{rpm},(c) 300 \mathrm{rpm}$, and (d) $400 \mathrm{rpm}$.

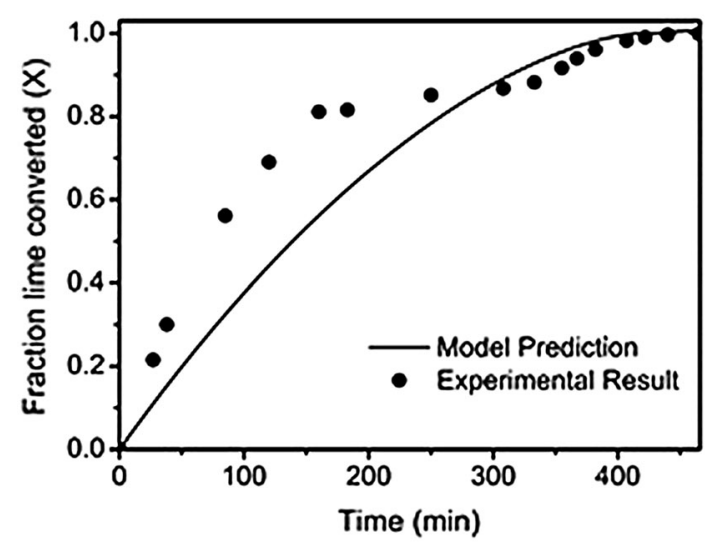

Fig. 9-Model predictions of fractional conversion of $\mathrm{CaO}(X)$ for a spherical specimen compared with the experimental data of Guo et al. ${ }^{[10]}$

value at $1773 \mathrm{~K}\left(1500{ }^{\circ} \mathrm{C}\right)$. For validation, model results are compared with experimental data reported by Matsushima et al. ${ }^{[4]}$ and a fairly good agreement between the two is obtained as evident from Figure 11.

\section{Slag composition}

Effects of slag composition on lime dissolution rates are modeled by considering its effects on $\gamma_{\mathrm{SiO}_{2}}$ and $\eta$. The effects of slag composition on $\gamma_{\mathrm{SiO}_{2}}$ are studied using Eq. [52] while those on $\eta$ are investigated using the

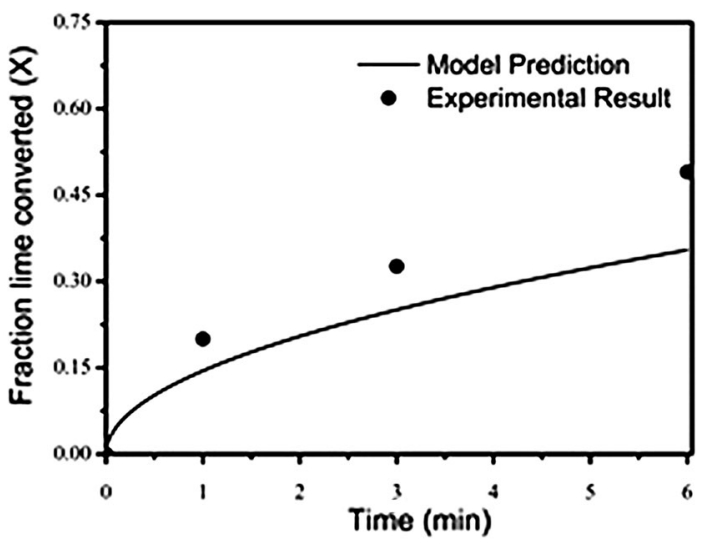

Fig. 10-Model predictions of fractional conversion of $\mathrm{CaO}(X)$ for a rectangular specimen compared with the experimental data of Deng et al. ${ }^{[7]}$

Viscosity module of FactSage version $6.4 .^{[18]}$ The results are analyzed by considering the effects of the two most important parameters that define the composition of LD slags:

\section{Slag basicity}

For fixed FeO content, the effects of slag basicity on dissolution rates are plotted in Figure 12 and compared with the experimental investigations of Matsushima et al. $^{[4]}$ and Hamano et al. ${ }^{[9]}$ As evident from Eq. [52], 


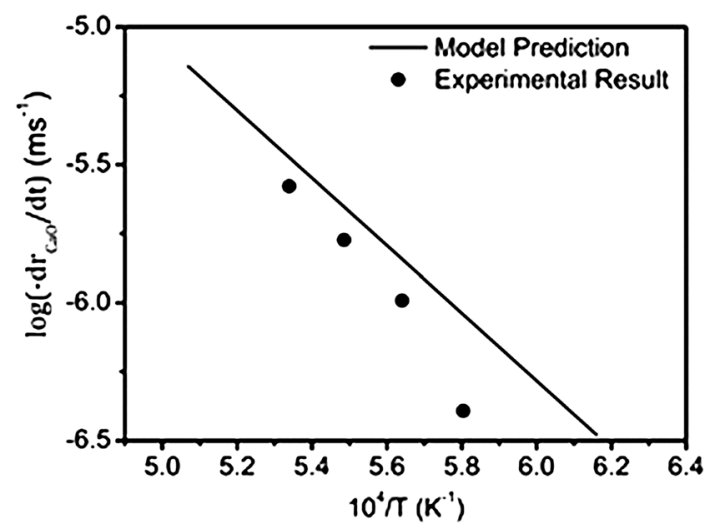

Fig. 11-Model predictions of the effects of temperature on dissolution rate of $\mathrm{CaO}$ compared with the experimental data of Matsushima et al. ${ }^{[4]}$

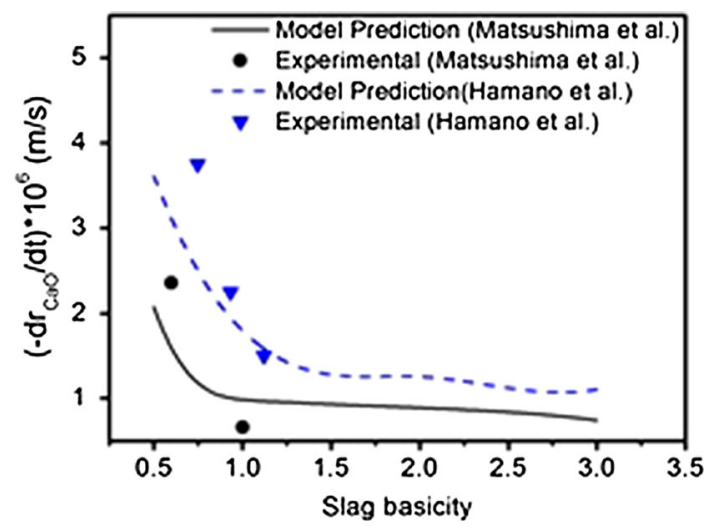

Fig. 12-Model predictions of the effects of slag basicity on dissolution rate of $\mathrm{CaO}$ compared with the experimental data of Matsushima et al. ${ }^{[4]}$ and Hamano et al. ${ }^{[9]}$

$\gamma_{\mathrm{SiO}_{2}}$ decreases with increasing basicity, and hence $C_{\mathrm{SiO}_{2}}^{e}$ increases. This, however, does not have a significant effect on the rate of dissolution for reasons previously discussed. Slag basicity has a much more pronounced effect on $\eta$. In the basicity range considered ( 0.5 to 3.0 ), as the slag basicity increases, $\eta$ initially increases, and then after a limiting basicity is reached, $\eta$ remains practically unchanged with basicity. Variation of $k_{\mathrm{m}}$ with basicity follows the reverse trend, and thus with increasing basicity, dissolution rates first decreases, and then remains practically constant. Model predictions correspond well with the experimental results of both sets of investigations at low values of basicity $(0.5$ to 1.0). ${ }^{[4,9]}$ At higher basicities, model results cannot be validated with experimental results since dissolution rates at higher basicities are not reported. ${ }^{[4,9]}$

\section{Slag $\mathrm{FeO}$ content}

Figure 13 shows the effects of $\mathrm{FeO}$ content of slags on dissolution rates at constant basicity. As in the previous case, model predictions are compared with the experimental data published by Matsuhima et al. ${ }^{[4]}$ and Hamano et al. ${ }^{[9]}$ With the increasing $\mathrm{FeO}$ content of slags, $\gamma_{\mathrm{SiO}_{2}}$ increases, and $C_{\mathrm{SiO}_{2}}^{e}$ decreases. This, however, has negligible effects on the rate of dissolution as previously discussed. $\mathrm{FeO}$ content has a much more significant effect on $\eta$. In the range currently considered (10 to 60 pct $\mathrm{FeO}$ ), $\eta$ greatly decreases with increase in slag $\mathrm{FeO}$ content but after about 50 pct $\mathrm{FeO}, \eta$ remains practically unchanged with further increase in $\mathrm{FeO}$. Thus $k_{\mathrm{m}}$ increases with the increasing $\mathrm{FeO}$ content till some limiting value (at around $50 \mathrm{pct}$ ) are reached after which it fairly remains constant. Dissolution rates follow a similar trend, as illustrated in Figure 13.

Experimental results published by Matsushima et al. ${ }^{[4]}$ and Hamano et al. ${ }^{[9]}$ indicate similar trends in the variation of dissolution rates with variation in $\mathrm{FeO}$ content of slags. In the case of Matsushima et al. ${ }^{[4]}$ model predictions agree very well with the experimental results in the range 20 to 40 pct $\mathrm{FeO}$. In Hamano et al.' ${ }^{[9]}$ case, however, the experimental studies report a much greater increase in rates with the increasing $\mathrm{FeO}$ in the range 40 to 55 pct $\mathrm{FeO}$, thus indicating that model predictions are not very accurate at higher $\mathrm{FeO}$ ranges $(>40$ pct). Error involved in calculating $\eta$ through FactSage calculations at higher $\mathrm{FeO}$ contents might be a possible reason for such deviation. For all practical purposes, however, dissolution rates at $\mathrm{FeO}$ content $>40$ pct is unimportant because $\mathrm{FeO}$ content in real steelmaking slags hardly becomes $>40$ pct. Nevertheless, further investigations on the reasons behind such deviations are necessary.

a. Lime particle size. To examine the effect of lime particle size on dissolution rate, the time for complete conversion of lime $(\tau)$ is calculated for three different geometries currently considered (termed $\tau_{\mathrm{c}}, \tau_{\mathrm{s}}$ and $\tau_{\mathrm{r}}$ for cylindrical, spherical, and rectangular specimens, respectively). Putting $X=1$ in Eqs. [44], [46], and [48], we get

$$
=\frac{\rho_{\mathrm{CaO}} r_{\mathrm{CaO}}^{0}\left(\frac{r_{\mathrm{CaO}}^{0} \ln \left(\frac{r_{\mathrm{CaO}}^{0}+\delta_{\mathrm{C}}}{r_{\mathrm{CaO}}^{0}}\right)}{4 \rho_{\mathrm{s}} D_{\mathrm{s}}}+\frac{r_{\mathrm{CaO}}^{0}}{8 \rho_{\mathrm{s}} D_{\mathrm{p}}}+\frac{1}{k_{\mathrm{f}}^{\prime}\left[C_{\mathrm{SiO}_{2}}^{p}-C_{\mathrm{SiO}_{2}}^{e}\right]}\right)}{1+\ln \left(\frac{\rho_{\mathrm{s}}-C_{\mathrm{SO}_{2}}^{e}}{\rho_{\mathrm{s}}-C_{\mathrm{SiO}_{2}}^{b}}\right)} .
$$

$$
\tau_{\mathrm{s}}=\frac{\rho_{\mathrm{CaO}} r_{\mathrm{CaO}}^{0}\left(\frac{\delta_{\mathrm{C}}}{6 \rho_{\mathrm{s}} D_{\mathrm{s}}}+\frac{r_{\mathrm{CaO}}^{0}}{12 \rho_{\mathrm{s}} D_{\mathrm{p}}}+\frac{1}{k_{\mathrm{f}}^{\prime}\left[C_{\mathrm{SiO}_{2}}^{p}-C_{\mathrm{SiO}_{2}}^{e}\right]}\right)}{1+\ln \left(\frac{\rho_{\mathrm{s}}-C_{\mathrm{SiO}_{2}}^{e}}{\rho_{\mathrm{s}}-C_{\mathrm{SiO}_{2}}^{b}}\right)} .
$$

$$
\tau_{\mathrm{r}}=\frac{\rho_{\mathrm{CaO}} l_{\mathrm{CaO}}^{0}\left(\frac{\delta_{\mathrm{C}}}{2 \rho_{\mathrm{s}} D_{\mathrm{s}}}+\frac{l_{\mathrm{CaO}}^{0}}{4 \rho_{\mathrm{s}} D_{\mathrm{p}}}+\frac{1}{k_{\mathrm{f}}^{\prime}\left[C_{\mathrm{SiO}_{2}}^{p}-C_{\mathrm{SiO}_{2}}^{e}\right]}\right)}{1+\ln \left(\frac{\rho_{\mathrm{s}}-C_{\mathrm{SiO}_{2}}^{e}}{\rho_{\mathrm{s}}-C_{\mathrm{SiO}_{2}}^{b}}\right)} .
$$




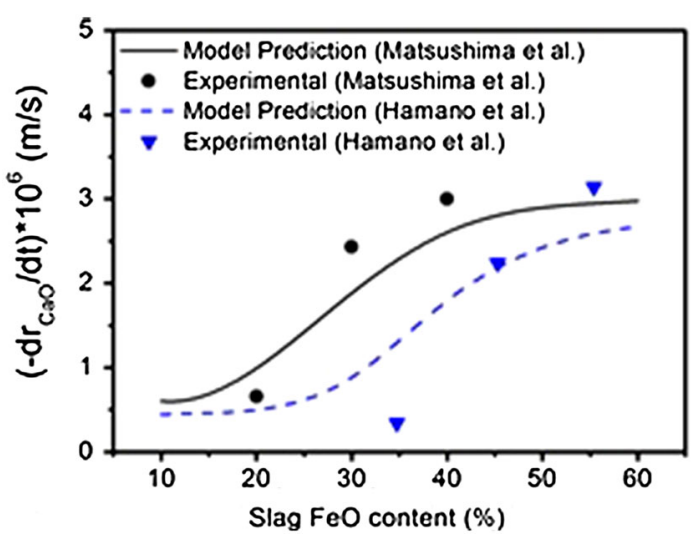

Fig. 13 - Model predictions of the effects of slag FeO content on dissolution rate of $\mathrm{CaO}$ compared with the experimental data of Matsushima et al. ${ }^{[4]}$ and Hamano et al. ${ }^{[9]}$

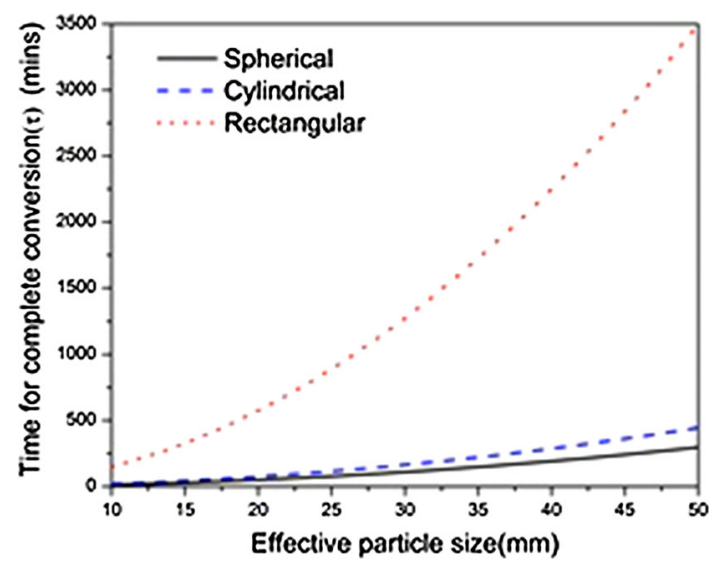

Fig. 14-Effect of particle size on the time required for complete conversion of $\mathrm{CaO}(\tau)$ for different geometries.

Figure 14 illustrates the effect of lime particle size on $\tau$ for the three geometries. For all three geometries, $\tau$ varies as the square of the lime particle size. This is also evident from Eqs. [54] through [56] and is characteristic of mixed control kinetics. It is also to be noted from Figure 14 that for the same particle size, $\tau_{\mathrm{s}}$ is the least, and $\tau_{\mathrm{r}}$ is maximum. $\tau_{\mathrm{c}}$ is only slightly higher than $\tau_{\mathrm{s}}$ and both $\tau_{\mathrm{c}}$ and $\tau_{\mathrm{s}}$ are much smaller than $\tau_{r}$. An explanation for this can be sought from Eqs. [54] through [56]. With the substitution of $l_{\mathrm{CaO}}^{0}=2 r_{\mathrm{CaO}}^{0}$ and assuming that the contributions from interfacial reaction control is negligible, it can be seen from Eqs. [55] and [56] that $\tau_{\mathrm{r}}$ is approximately twelve times $\tau_{\mathrm{s}}$. Using a similar argument, $\tau_{\mathrm{r}}$ can be found to be approximately eight times $\tau_{\mathrm{c}}$.

\section{Application to a Real Steelmaking Process}

In the preceding sections, a mixed control model for calculating the dissolution rate of lime in steelmaking slags has been developed. Also, the effects of process variables on dissolution rates have been examined. This model is now incorporated in the global model for LD

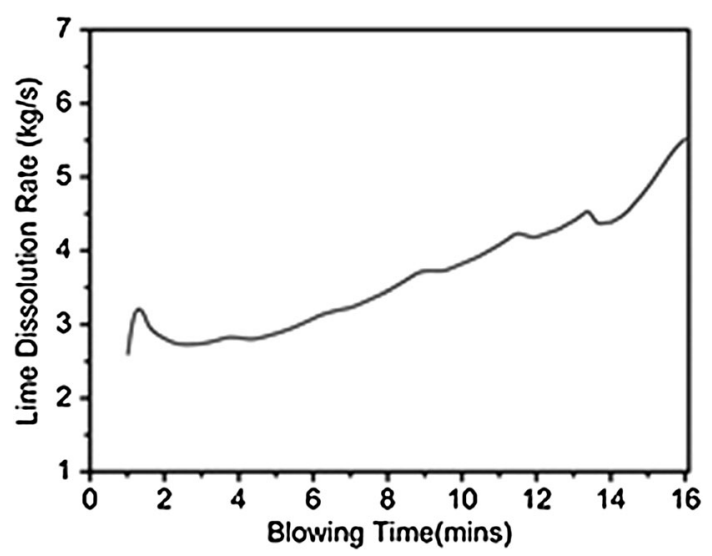

Fig. 15-Model predictions of variation in dissolution rate of $\mathrm{CaO}$ during blowing in a 160 -ton LD converter.

steelmaking, ${ }^{[1]}$ and in this section, the model predictions for variation in lime dissolution rates (calculated using the lime dissolution submodel) have been discussed. Finally, improvements in slag compositions (in terms of how closer they approach real-time values) with respect to the previous model have been analyzed.

\section{Variation in lime dissolution rate during the blow}

Figure 15 shows the variation in lime dissolution rate during blowing in a 160-ton LD converter. For a fixed particle size of the lime particle, dissolution rate depends on temperature, slag basicity, and $\mathrm{FeO}$ content. As already discussed, dissolution rates increases with the increasing temperature and $\mathrm{FeO}$ content and decreases with the increasing basicity. For the first 1 to 2 minutes of the blow, $\mathrm{FeO}$ content is very high (about $40 \mathrm{pct}$ ) and basicity is low (in the range 1.1 to 1.2). These factors result in high dissolution rates for the first 1 to 2 minutes even though the slag temperature is not high. As the blow proceeds, $\mathrm{FeO}$ content in slag starts decreasing and basicity increases. Both these factors result in a decrease in dissolution rate which reaches a minimum after about 5 minutes. After this, slag $\mathrm{FeO}$ content remains relatively constant for the major part of the blow. Both basicity and temperature, however, increases continually as the blow proceeds. These factors have counteracting effects on dissolution rates. As a result, lime dissolution rates remains fairly constant after about 5 minutes throughout the major part of the remaining blowing period. Slight increase in lime dissolution rate can be observed in Figure 15 because temperature has a much greater effect on dissolution rates as compared to slag basicity. Toward the very end of the blow, (after about 14 minutes from the start) $\mathrm{FeO}$ content starts increasing significantly. Temperatures are also very high and slag basicity slightly decreases due to the dilution effect of very high $\mathrm{FeO}$ content. All these factors favor the dissolution of lime in slag. Thus dissolution rates sharply increases in this period (14 to 16 minutes).

\section{Variation in slag compositions during the blow}

As previously discussed, the previous mode ${ }^{[1]}$ already predicted the variations in slag compositions during 


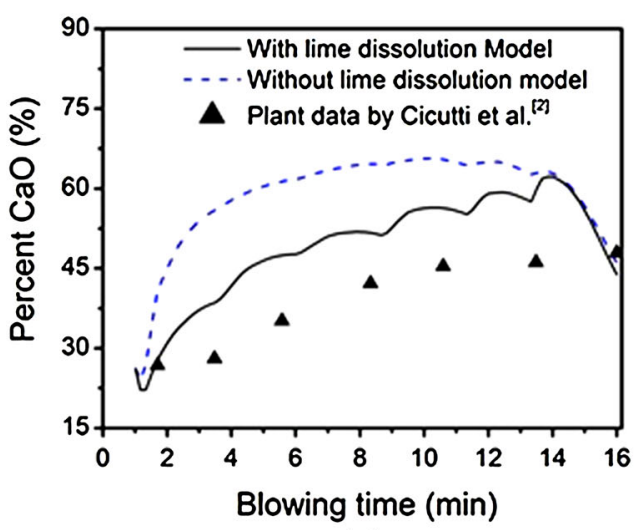

(a)

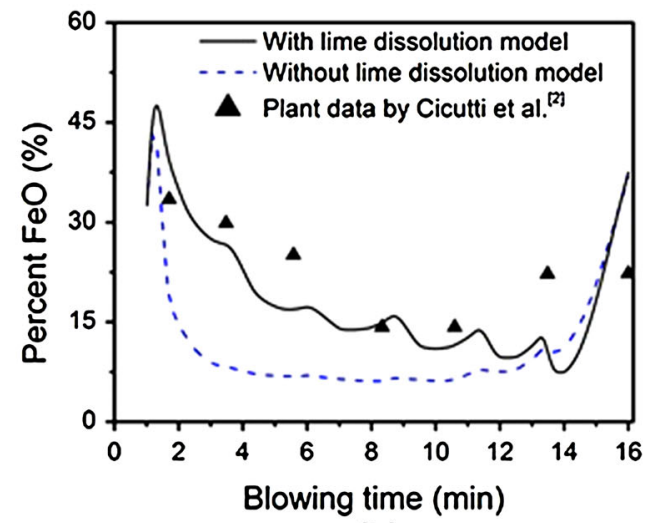

(b)

Fig. 16-Models predictions of variations in slag compositions during blowing in a 160-ton LD converter with and without the CaO dissolution model: (a) $\mathrm{CaO}$ and (b) $\mathrm{FeO}$.

blowing in a 160 -ton LD converter. This model aimed at improving the model predictions of slag compositions by incorporating a lime dissolution submodel into the global model. Figures 16(a) and (b) show the variations in slag compositions during the blow with and without the lime dissolution model. As evident from Figures 16(a) and (b), with the lime dissolution submodel, the global model predictions correspond much better with actual plant measurements. ${ }^{[2]}$ Towards the beginning of the blow dissolution rate of $\mathrm{CaO}$ is high, as previously discussed. However, as the blow proceeds, it starts to decrease. Consequently, lesser amount of $\mathrm{CaO}$ goes into the slag, and the overestimation in percent $\mathrm{CaO}$ is significantly reduced. Since percent FeO in slag depends on the dilution of slag by $\mathrm{CaO}$, the underestimation in $\mathrm{FeO}$ percent is also eliminated to a large extent. Similar to predictions of the previous model, percent $\mathrm{CaO}$ reaches a maximum, and percent $\mathrm{FeO}$ reaches a minimum after about 5 minutes from the start of the blow. However, with the lime dissolution model incorporated, the maximum in percent $\mathrm{CaO}$ is reached at a much lower value, and hence the minimum in percent $\mathrm{FeO}$ is reached at a much higher value. Afterward, the percent compositions of $\mathrm{CaO}$ and $\mathrm{FeO}$ remain practically constant, and this trend is observed in model predictions both with and without the lime dissolution model as well as in plant measurements by Cicutti et al. ${ }^{[2]}$ Toward the very end of the blow, (in the period 14 to 16 minutes after the blow-start), there is not much improvement in model predictions with the incorporation of the lime dissolution model. This deviation, however, is attributed more to a demerit inherent to the global model. In the end-blow regime, the amount of hot metal in the emulsion becomes too low, and hence, the consumption of $\mathrm{FeO}$ due to reactions is very less, thus resulting in very high $\mathrm{FeO}$ content in the slag. ${ }^{[1]}$ Further refinement with regard to this aspect may be necessary to obtain realistic predictions during the final stages of the blow. Very high rates of lime dissolution in these stages may compensate for the high $\mathrm{FeO}$ content thus bringing down the percent
$\mathrm{FeO}$ values by dilution effects. Such high rates of dissolution, however, are not obtained using the present submodel even during the very late stages of the blow.

\section{CONCLUSION}

The current study was aimed to develop a model for dissolution of lime in steelmaking slags based on the assumption that $\mathrm{CaO}$ reacts with $\mathrm{SiO}_{2}$ in slags to form solid $2 \mathrm{CaO} \cdot \mathrm{SiO}_{2}$. A three-step kinetic process for the dissolution of lime has been hypothesized. Critically analyzing experimental data published by other researchers, it has been argued that the observed kinetics cannot be suitably explained if any one of the three (hypothetical) reaction steps is rate controlling. Thus, mixed control models have been proposed in the current study for calculating lime dissolution rates. Integrated rate equations for each of the three rate-controlling mechanisms are first obtained, and then the rate laws for mixed control kinetics have been derived. Proposed mixed control models for different lime geometries are first validated using experimental data published elsewhere. Then, the effects of temperature, slag basicity, slag $\mathrm{FeO}$ content, and lime particle size on dissolution rates have been analyzed and validated with experimental results of other researchers. Finally, this model has been incorporated in the already existing global model for LD steelmaking. Incorporation of the submodel into the global model enabled the calculation of lime dissolution rates dynamically during blowing in a 160-ton LD steelmaking converter. More importantly, considerable improvements in predictions of slag compositions have been observed. With the inclusion of the lime-dissolution submodel, predictions for percent $\mathrm{CaO}$ and percent $\mathrm{FeO}$ corroborate much better with the industrial results for a major part of the blow. In the end-blow regime, not much improvement in model predictions can be achieved, thus indicating that further refinement of the model may be required. 


\section{NOMENCLATURES}

$b \quad$ Breadth of rectangular $\mathrm{CaO}$ specimen $(\mathrm{m})$

$d_{\mathrm{CaO}} \quad$ Diameter of spherical/cylindrical $\mathrm{CaO}$ specimen at any time $t(\mathrm{~m})$

$k_{\mathrm{b}}^{\prime} \quad$ Modified backward reaction rate constant for the reaction

$2 \mathrm{CaO}(\mathrm{s})+\left(\mathrm{SiO}_{2}\right)=2 \mathrm{CaO} \cdot \mathrm{SiO}_{2}(\mathrm{~s})(\mathrm{m} / \mathrm{s})$

$k_{\mathrm{f}}^{\prime} \quad$ Modified forward reaction rate constant for the reaction

$2 \mathrm{CaO}(\mathrm{s})+\left(\mathrm{SiO}_{2}\right)=2 \mathrm{CaO} \cdot \mathrm{SiO}_{2}(\mathrm{~s})(\mathrm{m} / \mathrm{s})$

$k_{\mathrm{m}} \quad$ Mass-transfer co-efficient of $\mathrm{SiO}_{2}$

in slag $(\mathrm{m} / \mathrm{s})$

$l_{\mathrm{CaO}} \quad$ Length of rectangular $\mathrm{CaO}$ specimen at any time $t(\mathrm{~m})$

$l_{\mathrm{CaO}}^{0} \quad$ Initial length of rectangular $\mathrm{CaO}$ specimen (m)

$r_{\mathrm{CaO}} \quad$ Radius of spherical/cylindrical $\mathrm{CaO}$ specimen at time $t(\mathrm{~m})$

$r_{\mathrm{CaO}}^{0} \quad$ Initial radius of $\mathrm{CaO}$ particle (for spherical/cylindrical specimen) (m)

$u \quad$ Linear velocity of $\mathrm{CaO}$ particle (for rotating specimen) $(\mathrm{m} / \mathrm{s})$

$-v_{\mathrm{CaO}}$ Molar rate of reaction of $\mathrm{CaO}$ as per the reaction $2 \mathrm{CaO}(\mathrm{s})+\left(\mathrm{SiO}_{2}\right)=2 \mathrm{CaO} \cdot \mathrm{SiO}_{2}(\mathrm{~s})$ $\left(\mathrm{mol} / \mathrm{m}^{2} \mathrm{~s}\right)$

$w \quad$ Width of rectangular $\mathrm{CaO}$ specimen (m)

$x_{j} \quad$ Mole-fraction of component $j$ in slag (-)

$C_{\mathrm{SiO}_{2}}^{b} \quad$ Molar concentration of $\mathrm{SiO}_{2}$ in the bulk slag $\left(\mathrm{mol} / \mathrm{m}^{3}\right)$

$C_{\mathrm{SiO}_{2}}^{e} \quad$ Molar concentration of $\mathrm{SiO}_{2}$ at the interface between $\mathrm{CaO}$ and $2 \mathrm{CaO} \cdot \mathrm{SiO}_{2}\left(\mathrm{~mol} / \mathrm{m}^{3}\right)$

$C_{\mathrm{SiO}_{2}}^{p} \quad$ Molar concentration of $\mathrm{SiO}_{2}$ at the interface between $2 \mathrm{CaO} \cdot \mathrm{SiO}_{2}$ and slag-film $\left(\mathrm{mol} / \mathrm{m}^{3}\right)$

$C_{\mathrm{SiO}_{2}} \quad$ Molar concentration of $\mathrm{SiO}_{2}\left(\mathrm{~mol} / \mathrm{m}^{3}\right)$

$D_{\mathrm{p}} \quad$ Diffusivity of $\mathrm{SiO}_{2}$ through $2 \mathrm{CaO} \cdot \mathrm{SiO}_{2}$ (s) layer $\left(\mathrm{m}^{2} / \mathrm{s}\right)$

$D_{\mathrm{s}} \quad$ Diffusivity of $\mathrm{SiO}_{2}$ in slag $\left(\mathrm{m}^{2} / \mathrm{s}\right)$

$D_{0} \quad$ Pre-exponential factor in the Arrhenius relation for $D_{\mathrm{s}}\left(\mathrm{m}^{2} / \mathrm{s}\right)$

$E_{\eta} \quad$ Activation energy for viscous flow of slag $(\mathrm{J} / \mathrm{mol})$

$E_{\mathrm{S}} \quad$ Activation energy for diffusion of $\mathrm{SiO}_{2}$ in slag $(\mathrm{J} / \mathrm{mol})$

$J_{\mathrm{SiO}_{2}(i)}^{*} \quad$ Molecular flux of $\mathrm{SiO}_{2}$ in the $i$ direction (mol/ $\left.\mathrm{m}^{2} \mathrm{~s}\right)$

$L \quad$ Length of cylindrical $\mathrm{CaO}$ particle $(\mathrm{m})$

$N_{\mathrm{SiO}_{2}(i)} \quad$ Combined molar flux of $\mathrm{SiO}_{2}$ in the $i$ direction $\left(\mathrm{mol} / \mathrm{m}^{2} \mathrm{~s}\right)$

$R \quad$ Universal gas constant $(\mathrm{J} / \mathrm{mol} \mathrm{K})$

Re Reynolds number (-)

Sc $\quad$ Schidmt number $(-)$

$T \quad$ Temperature (K)

$W_{\mathrm{SiO}_{2}(i)} \quad$ Molar rate of diffusion of $\mathrm{SiO}_{2}$ in the $i$

direction $(\mathrm{mol} / \mathrm{s})$

$X \quad$ Fractional conversion of $\mathrm{CaO}(-)$

\section{GREEK SYMBOLS}

$\alpha$

\section{$\beta$}

$\gamma_{\mathrm{SiO}_{2}}$

$\delta_{\mathrm{C}}$

$(\mathrm{m})$

$\eta \quad$ Viscosity of $\operatorname{slag}(\mathrm{Pa} \mathrm{s})$

$\eta_{0} \quad$ Pre-exponential factor in the Arrhenius relation for $\eta$ (Pa s)

$\rho_{\mathrm{CaO}} \quad$ Molar density of $\mathrm{CaO}\left(\mathrm{mol} / \mathrm{m}^{3}\right)$

$\rho_{\mathrm{s}} \quad$ Molar density of slag $\left(\mathrm{mol} / \mathrm{m}^{3}\right)$

$\tau \quad$ Time required for complete conversion of $\mathrm{CaO}$ (s)

$\varphi$ $2 \mathrm{Cao} \cdot \mathrm{SiO}_{2}$ and through the slag (-)

\section{REFERENCES}

1. R. Sarkar, P. Gupta, S. Basu, and N.B. Ballal: Metall. Mater Trans. B, 2015, vol. 46B, pp. 961-76.

2. C. Cicutti, M. Valdez, T. Pérez, J. Petroni, A. Gómez, R. Donayo, and L. Ferro: Proc. $6^{\text {th }}$ International Conference on Molten Slags, Fluxes and Salts, Stockholm City, 2000, p. 367.

3. S.K. Choudhary, S.N. Lenka, and A. Ghosh: Ironmak. Steelmak., 2007, vol. 37 (4), pp. 343-49.

4. M. Matsushima, S. Yadoomaru, K. Mori, and Y. Kawai: Trans. Iron Steel Inst. Jpn., 1977, vol. 17, pp. 442-49.

5. T. Hamano, S. Fukagai, and F. Tsukihashi: Iron Steel Inst. Jpn. Int., 2006, vol. 46 (4), pp. 490-95.

6. S. Amini, M. Brungs, and O. Ostrovski: Iron Steel Inst. Jpn. Int., 2007, vol. 47 (1), pp. 32-37.

7. T. Deng and D. Sichen: Metall. Mater Trans. B, 2012, vol. 43B, pp. $578-86$.

8. Z.S. Li, M. Whitwood, S. Millman, and J. van Boggelen: Ironmak. Steelmak., 2014, vol. 41 (2), pp. 112-20.

9. T. Hamano, M. Horibe, and K. Ito: Iron Steel Inst. Jpn. Int., 2004, vol. 44 (2), pp. 263-67.

10. M. Guo, Z. Sun, X. Guo and B. Blanpain: Proc. 2013 Int. Symp. on Liquid Metal Processing and Casting, TMS, Austin, TX. 2013, pp. 101-108.

11. S.Y. Kitamura, H. Shibata, and N. Maruoka: Steel Res. Int., 2008, vol. 79 (8), pp. 586-90.

12. A.K. Shukla, B. DeO, S. Millman, B. Snoeijer, A. Overbosch, and A. Kapilashrami: Steel Res. Int., 2010, vol. 81 (11), pp. 940-48.

13. N. Dogan, G.A. Brooks, and M.A. Rhamdhani: Iron Steel Inst. Jpn. Int., 2009, vol. 49 (10), pp. 1474-82.

14. R.B. Bird, W.E. Stewart, and E.N. Lightfoot: Transport Phenomena, 2nd ed., Wiley, New York, 2002, pp. 536-37.

15. O. Levenspiel: Chemical Reaction Engineering, 3rd ed., Wiley, New York, 1999, p. 481.

16. A. Ghosh and S. Ghosh: A Textbook of Metallurgical Kinetics, PHI Learning Pvt. Ltd., Delhi, 2014, pp. 166-68.

17. M. Kosaka and S. Minowa: Tetsu-to-Hagané, 1965, vol. 51 (2), pp. 218-25.

18. FactSage: Version 6.4, Database FToxid, Thermfact and GTT Technologies, 2013.

19. O. Kubaschewski and C.B. Alcock: Metallurgical Thermochemistry, 5th ed., Permagon Press, Oxford, 1979, pp. 237-42.

20. M.D. Dolan and R.F. Johnston: Metall. Mater Trans. B, 2004, vol. 35B, pp. 675-84. 